\title{
SARS-CoV-2-reactive T cells in healthy donors and patients with COVID-19
}

https://doi.org/10.1038/s41586-020-2598-9

Received: 9 April 2020

Accepted: 22 July 2020

Published online: 29 July 2020

Check for updates

\author{
Julian Braun ${ }^{1,2,17}$, Lucie Loyal ${ }^{1,2,17}$, Marco Frentsch ${ }^{3,4,17}$, Daniel Wendisch ${ }^{5}$, Philipp Georg ${ }^{5}$, \\ Florian Kurth $^{5,6,7}$, Stefan Hippenstiel ${ }^{5}$, Manuela Dingeldey ${ }^{1,2}$, Beate Kruse ${ }^{1,2}$, Florent Fauchere ${ }^{1,2}$, \\ Emre Baysal ${ }^{1,2}$, Maike Mangold ${ }^{1,2}$, Larissa Henze ${ }^{1,2}$, Roland Lauster ${ }^{1,8}$, Marcus A. Mall ${ }^{4,9}$, \\ Kirsten Beyer ${ }^{9}$, Jobst Röhmel ${ }^{9}$, Sebastian Voigt ${ }^{10}$, Jürgen Schmitz ${ }^{11}$, Stefan Miltenyi ${ }^{11}$, \\ Ilja Demuth ${ }^{12}$, Marcel A. Müller ${ }^{13}$, Andreas Hocke ${ }^{5}$, Martin Witzenrath ${ }^{5}$, Norbert Suttorp ${ }^{5}$, \\ Florian Kern ${ }^{14,15}$, Ulf Reimer ${ }^{15}$, Holger Wenschuh ${ }^{15}$, Christian Drosten ${ }^{4,13}$, Victor M. Corman ${ }^{13}$, \\ Claudia Giesecke-Thiel ${ }^{16,18 \bowtie}$, Leif Erik Sander ${ }^{5,18} \bowtie$ \& Andreas Thiel ${ }^{1,2,18} \bowtie$
}

\begin{abstract}
Severe acute respiratory syndrome coronavirus 2 (SARS-CoV-2) has caused the rapidly unfolding coronavirus disease 2019 (COVID-19) pandemic ${ }^{1,2}$. Clinical manifestations of COVID-19 vary, ranging from asymptomatic infection to respiratory failure. The mechanisms that determine such variable outcomes remain unresolved. Here we investigated $\mathrm{CD}^{+} \mathrm{T}$ cells that are reactive against the spike glycoprotein of SARS-CoV-2 in the peripheral blood of patients with COVID-19 and SARS-CoV-2-unexposed healthy donors. We detected spike-reactive $\mathrm{CD} 4^{+} \mathrm{T}$ cells not only in $83 \%$ of patients with COVID-19 but also in 35\% of healthy donors. Spike-reactive CD4 ${ }^{+} \mathrm{T}$ cells in healthy donors were primarily active against $C$-terminal epitopes in the spike protein, which show a higher homology to spike glycoproteins of human endemic coronaviruses, compared with $\mathrm{N}$-terminal epitopes. Spike-protein-reactive $\mathrm{T}$ cell lines generated from SARS-CoV-2-naive healthy donors responded similarly to the $\mathrm{C}$-terminal region of the spike proteins of the human endemic coronaviruses $229 \mathrm{E}$ and OC43, as well as that of SARS-CoV-2. This results indicate that spike-protein cross-reactive T cells are present, which were probably generated during previous encounters with endemic coronaviruses. The effect of pre-existing SARS-CoV-2 cross-reactive T cells on clinical outcomes remains to be determined in larger cohorts. However, the presence of spike-protein cross-reactive $T$ cells in a considerable fraction of the general population may affect the dynamics of the current pandemic, and has important implications for the design and analysis of upcoming trials investigating COVID-19 vaccines.
\end{abstract}

The COVID-19 pandemic poses a threat to public health and the global economy as the number of cases and COVID-19-related deaths increases worldwide $^{1,2}$. COVID-19 is routinely diagnosed by the detection of SARS-CoV-2 RNA in nasopharyngeal swabs using $\mathrm{PCR}^{3}$, the detection of which is reliable during the acute phase of COVID-19 ${ }^{4,5}$. However, the limited availability of tests and the preferential testing of patients with symptoms has probably led to a marked underestimation of the infection burden and overestimation of fatality rates $^{6}$. Serological analysis of SARS-CoV-2-induced humoral immunity could reveal asymptomatic infections, but it is not yet widely applied ${ }^{7,8}$ and is complicated by the fact that coronavirus-induced antibody responses are variable and short-lived ${ }^{9,10}$. Coronavirus-induced cellular immunity is predicted to be more sustained, but remains poorly characterized. However, several T cell epitopes in the structural proteins of coronaviruses have been predicted or identified ${ }^{9,11-13}$. Notably, T helper $\left(T_{H}\right)$ cell responses and the generation of neutralizing antibodies may be interdependent ${ }^{9,14}$. Studies of the SARS-CoV epidemic in 2002-2003 have shown that adaptive immune responses directed against the spike glycoprotein (S) were protective $\mathrm{e}^{9,15,16}$. Therefore, the induction of SARS-CoV-2-specific CD4 ${ }^{+}$ T cells is likely to be critical in the instruction of affinity-maturated and potentially protective antibody responses ${ }^{17}$. We therefore examined the presence, frequencies and phenotypic characteristics of SARS-CoV-2 S-reactive T cells in patients with COVID-19 compared with SARS-CoV-2-unexposed healthy donors (HDs).

${ }^{1}$ Si-M/'Der Simulierte Mensch', Technische Universität Berlin and Charité-Universitätsmedizin Berlin, Berlin, Germany. ${ }^{2}$ Regenerative Immunology and Aging, BIH Center for Regenerative

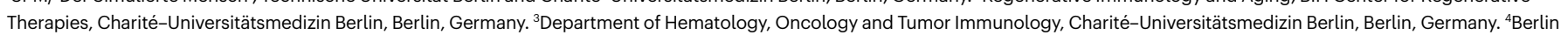

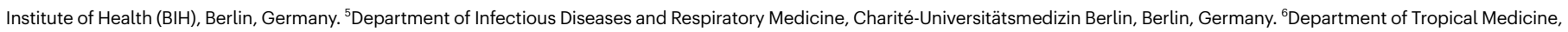

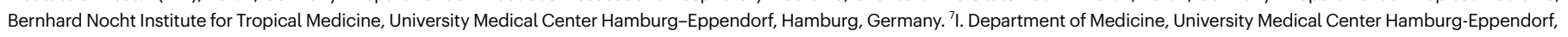

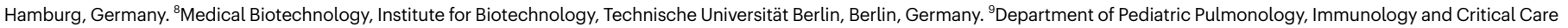
Medicine, Charité-Universitätsmedizin Berlin, Berlin, Germany. ${ }^{10}$ Department of Infectious Diseases, Robert Koch Institut, Berlin, Germany. ${ }^{11}$ Miltenyi Biotec, Bergisch Gladbach, Germany. ${ }^{12}$ Interdisciplinary Metabolism Center, Biology of Aging (BoA) group, Charité-Universitätsmedizin Berlin, Berlin, Germany. ${ }^{13}$ Institute of Virology, Charité-Universitätsmedizin Berlin, Berlin, Germany. ${ }^{14}$ Department of Clinical and Experimental Medicine, Brighton and Sussex Medical School, Brighton, UK. ${ }^{15}$ JPT Peptide Technologies, Berlin, Germany. ${ }^{16}$ Max Planck Institute for Molecular Genetics, Berlin, Germany. ${ }^{17}$ These authors contributed equally: Julian Braun, Lucie Loyal, Marco Frentsch. ${ }^{18}$ These authors jointly supervised this work: Claudia Giesecke-Thiel, Leif Erik Sander, Andreas Thiel. ${ }^{凶}$ e-mail: giesecke@molgen.mpg.de; leif-erik.sander@charite.de; andreas.thiel@charite.de 


\section{Identification of $S$-reactive $\mathrm{CD4}^{+} \mathrm{T}$ cells}

We identified S-reactive $C D 4^{+} \mathrm{T}$ cells by flow cytometry according to their expression of CD40L and 4-1BB after in vitro stimulation with $\mathrm{S}$ peptides. To this end, we designed two peptide pools (15 amino acids with 11 amino acid overlaps) that spanned the entire S protein and that contained different amounts of putative MHC-II epitopes based on epitopes identified in SARS-CoV ${ }^{11-13}$ (Fig. 1a). SARS-CoV-2 S-peptide pool PepMix 1 (hereafter, $\mathrm{S}$-I) spans the $\mathrm{N}$-terminal part (amino acid residues 1-643) and includes 21 predicted SARS-CoV MHC-II epitopes (Fig. 1a, Extended Data Fig. 1 and Extended Data Table 1). The second peptide pool PepMix 2 (S-II) covered the C-terminal portion (amino acid residues 633-1273) and includes 13 predicted SARS-CoV MHC-II epitopes (Fig. 1a, Extended Data Fig. 1 and Extended Data Table1). The peptides of the receptor-binding domain in subunit S1, which represents a major target of neutralizing antibodies, are included in S- $\mathrm{I}^{18,19}$.

For antigen-specific stimulation, peripheral blood mononuclear cells from patients and HDs were stimulated for $16 \mathrm{~h}$ with S-I and S-II peptide pools (for characteristics of patients and HDs, see Table 1 and Extended Data Tables 2,3). Antigen-reactive $\mathrm{CD}^{+}{ }^{+} \mathrm{T}$ cells were identified by co-expression of $4-1 B B$ and $C D 40 \mathrm{~L}$, which enables the sensitive detection of S-reactive $\mathrm{CD} 4^{+} \mathrm{T}$ cells re-activated by $\mathrm{T}$ cell receptor engagement ex vivo ${ }^{20-22}$ (Fig. 2a, Extended Data Fig. 2 and Supplementary Information). In 12 (67\%) and 15 (83\%) out of 18 patients, we detected $\mathrm{CD} 4^{+} \mathrm{T}$ cells that reacted against the S-I and S-II peptide pools, respectively (Fig. 2b, d, e). Most patients with COVID-19 with critical disease showed no reactivity to the S-I peptide pool (Extended Data Fig. 3).

Notably, S-II-reactive $\mathrm{CD} 4^{+} \mathrm{T}$ cells-although at slightly lower frequencies compared with patients with COVID-19-could also be detected in 24 out of $68 \mathrm{HDs}$ (35\%), who are hereafter referred to as reactive healthy donors (RHDs) (Fig. 2c-e). S-I-reactive CD4 ${ }^{+} \mathrm{T}$ cells could be detected in only 6 out of the 24 RHDs, that is, in $5.8 \%$ of all HDs (Fig. 2d, e). All HDs were negative for IgG antibodies that were specific to the $S 1$ subunit, in contrast to patients with COVID-19 (Fig. 2f). We further ruled out early SARS-CoV-2 infection at initial sampling by (1) direct standard diagnosis using PCR in 10 RHDs (data not shown); (2) serological testing (Fig. 2f); and (3) by repeated serological testing at least 28 days later for 65 out of 68 HDs (Extended Data Fig. 4).

We further phenotypically and functionally characterized S-reactive $\mathrm{CD}^{+} \mathrm{T}$ cells in additional patients with COVID-19 (Extended Data Table 4) and RHDs. Notably, in both groups, SARS-CoV-2 S-II-reactive
Table 1 | Baseline characteristics of all donors

\begin{tabular}{|c|c|c|c|c|c|}
\hline Cohort & $\begin{array}{l}\text { Gender } \\
\text { distribution } \\
\text { (\%) }\end{array}$ & $\begin{array}{l}\text { Average age } \\
\text { (range) }\end{array}$ & $\begin{array}{l}\text { Disease } \\
\text { severity }\end{array}$ & $\begin{array}{l}\text { ICU } \\
\text { (yes/ } \\
\text { no) }\end{array}$ & $\begin{array}{l}\text { Average } \\
\text { sampling } \\
\text { day (range) }\end{array}$ \\
\hline $\begin{array}{l}\text { Patients } \\
\text { with } \\
\text { COVID-19 }\end{array}$ & $\begin{array}{l}\text { Male, } 72 \% ; \\
\text { female, } 28 \%\end{array}$ & $\begin{array}{l}52.6 \text { years } \\
(21-81 \text { years) }\end{array}$ & $\begin{array}{l}\text { Mild, } \\
38.9 \% ; \\
\text { severe, } \\
27.8 \% ; \\
\text { critical, } \\
33.3 \%\end{array}$ & $\begin{array}{l}\text { No, } \\
44.4 \% ; \\
\text { yes, } \\
55.6 \%\end{array}$ & $\begin{array}{l}14.9 \text { days } \\
\text { (2-39 days) }\end{array}$ \\
\hline $\begin{array}{l}\text { Healthy } \\
\text { donors }\end{array}$ & $\begin{array}{l}\text { Male, } 31 \% ; \\
\text { female, } 59 \%\end{array}$ & $\begin{array}{l}41.9 \\
\text { (20-64 years) }\end{array}$ & NA & NA & NA \\
\hline
\end{tabular}

$\mathrm{CD}^{+} \mathrm{T}$ cells exhibited a memory phenotype and a significant proportion of the cells expressed IFN $\gamma$, indicative of $\mathrm{T}_{\mathrm{H}} 1$ polarization (Fig. $2 \mathrm{~g}$ and Extended Data Fig. 5a-d). Most S-reactive CD4 ${ }^{+} \mathrm{T}$ cells expressed IL-2 but only few cells expressed IL-17A (Extended Data Fig. 5a-d). Frequencies of S-II-reactive CD4 ${ }^{+} \mathrm{T}$ cells that expressed IFN $\gamma$ were similar in patients and RHDs (Fig. 2g). Testing for TNF expression revealed that S-II-reactive IFN $\gamma^{+} \mathrm{CD} 4^{+} \mathrm{T}$ cells from RHDs mostly co-expressed $\mathrm{TNF}$, whereas S-II-reactive IFN $\gamma^{+} \mathrm{CD} 4^{+} \mathrm{T}$ cells from patients with COVID19 showed heterogenous TNF expression patterns (Extended Data Fig. 5e). This probably reflects the different disease stages of the acute SARS-CoV-2 infection of the individual patients included in our study. These results show that S-reactive $\mathrm{CD} 4^{+} \mathrm{T}$ cells with a predominantly $\mathrm{T}_{\mathrm{H}} 1$ memory phenotype are present not only in patients with COVID-19 but also in seronegative SARS-CoV-2-unexposed HDs.

\section{S-reactive T cells in RHDs are cross-reactive to hCoVs}

S-reactive $\mathrm{CD}^{+}{ }^{+} \mathrm{T}$ cells from patients with COVID-19 equally targeted both the $\mathrm{N}$-terminal (S-I) and $\mathrm{C}$-terminal peptide pools (S-II) of S, whereas S-reactive CD4 ${ }^{+} \mathrm{T}$ cells from RHDs reacted significantly more strongly to the S-II peptide pool (Fig. 2d). S-II exhibits a higher homology to the human endemic coronaviruses (hCoVs; known as 'common cold' viruses) 229E, NL63, OC43 and HKU1 with regard to the SARS-CoV MHC-II epitopes, compared to the S-I peptide pool (Extended Data Table 1 and Extended Data Fig. 1). This suggests that S-reactivity in SARS-CoV-2-naive HDs originated from previous immune responses a

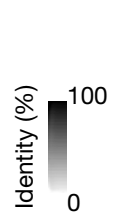

S-I
S-II

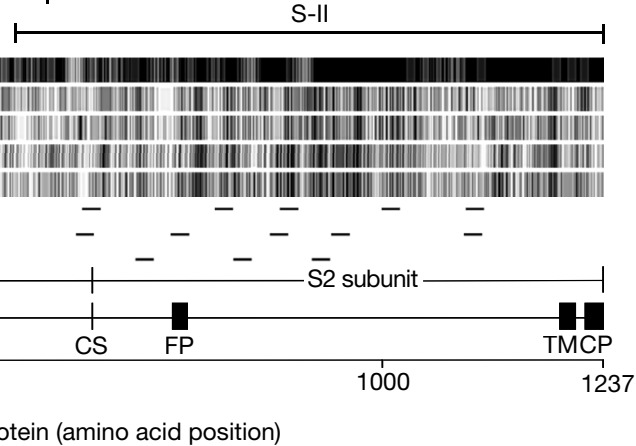

b

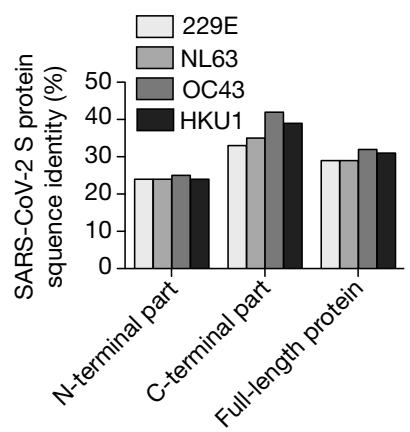

Fig. 1 | Structural domains, homology and MHC-II epitopes of the SARS-CoV-2 S protein. a, The S protein of SARS-CoV-2 (1,237 amino acids) is separated at the cleavage site (CS) into subunit $\mathrm{S1}$, which comprises the receptor-binding domain (RBD), and subunit $\mathrm{S} 2$ which contains the fusion peptide (FP), the transmembrane domain (TM) and the cytoplasmic peptide (CP). Sequence homology of S proteins of SARS-CoV-2, SARS-CoV and hCoV strains NL63, 229E, HKU1 and OC43 was calculated as the percentage of amino acid identity in sliding windows of 10 amino acids and is depicted as grey vertical lines. Predicted SARS-CoV MHC-II epitopes are indicated as small horizontal lines. Sequences and references are listed in Extended Data Table 1. Homology is depicted for each reported MHC-II epitope in Extended Data Fig. 1. S-I spans the $\mathrm{N}$-terminal region of S and S-II spans the $\mathrm{C}$-terminal part of $\mathrm{S}$, as indicated above the alignment. b. Proportion of sequence identity of the $\mathrm{N}$-terminal and $\mathrm{C}$-terminal parts of the S protein of SARS-CoV-2 and the S proteins of hCoV strains NL63, 229E, HKU1 and OC43. 


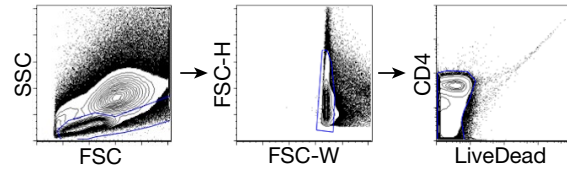

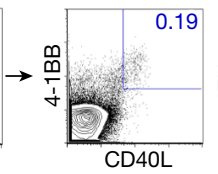

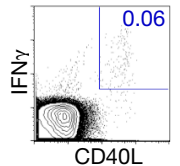

$P=0.0031$

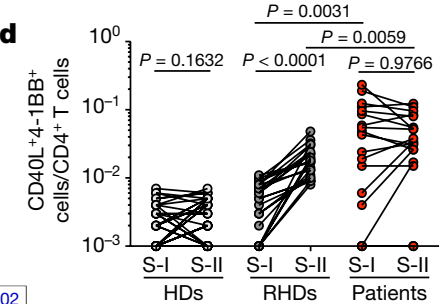

b

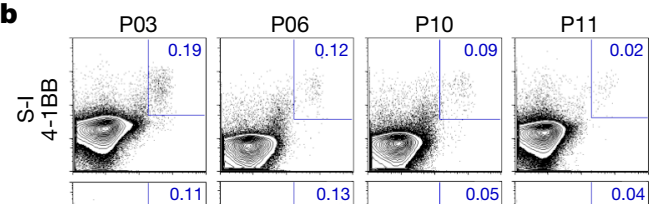

c $\mathrm{HD} 40$

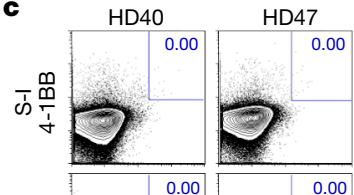

RHD35

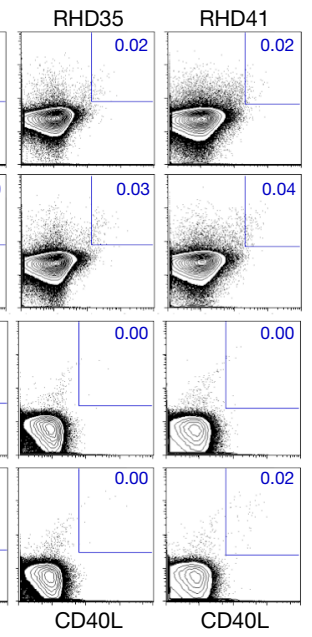

i

02 के

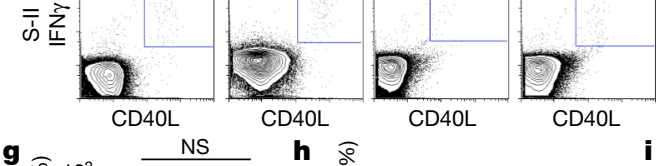

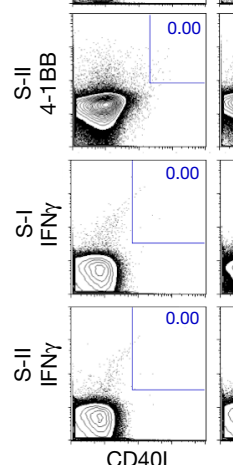

e

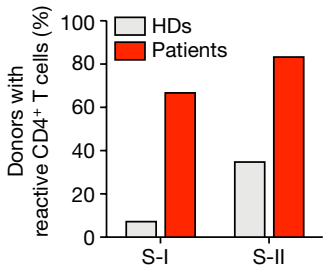

$\mathbf{f}$

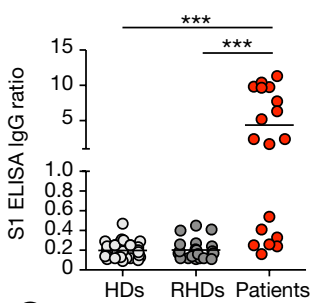

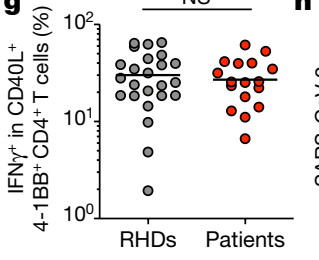
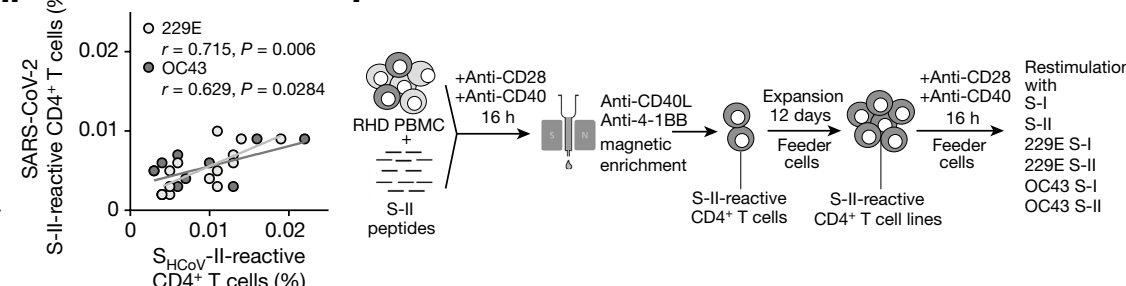

j

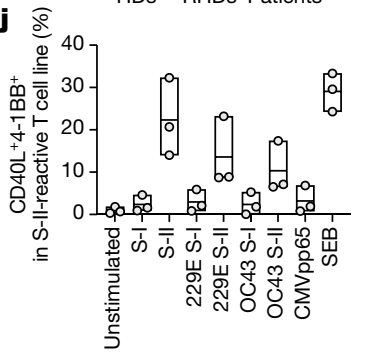

Fig. 2 | SARS-CoV-2 S-reactive CD4 ${ }^{+} T$ cells in patients with CoVID-19 and

HDs. a, Gating strategy to detect SARS-CoV-2S-reactive $C D 4^{+} \mathrm{T}$ cells after in vitro stimulation for $16 \mathrm{~h}$ with SARS-CoV-2 S-I and S-II peptide pools. Representative data of one patient with COVID-19 are shown. FSC, forward scatter; FSC-H, forward scatter height; FSC-W, forward scatter width; SSC, side scatter. b, c, Representative plots of CD4OL and 4-1BB as well as CD40L and IFN $\gamma$ expression on $C D 4^{+} \mathrm{T}$ cells of patients with COVID-19 (P), HDs and RHDs after $16 \mathrm{~h}$ of in vitro stimulation with S-I or S-II peptide pools. Numbers show the percentage of double-positive cells out of the total number of $\mathrm{CD} 4^{+} \mathrm{T}$ cells. d, Comparison of S-I- or S-II-reactive $\mathrm{CD}^{2} \mathrm{~L}^{+} 4-1 \mathrm{BB}^{+} \mathrm{CD}^{+}{ }^{+} \mathrm{T}$ cell frequencies in $\mathrm{HDs}(n=44)$, RHDs $(n=24)$ and patients $(n=18)$. e, Percentage of patients and HDs with S-I-reactive and S-II-reactive CD4 ${ }^{+} \mathrm{T}$ cells. $\mathrm{f}$, SARS-CoV-2 S1 serology of HDs $(n=44)$, RHDs $(n=24)$ and patients $(n=18) .{ }^{* * *} P<0.0001 . \mathrm{g}$, Comparison of the frequencies of

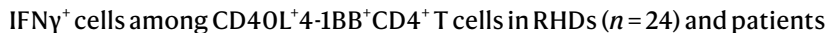
$(n=18)$. NS, not significant. $h$, Correlation between SARS-CoV-2 S-II and $\mathrm{S}_{\mathrm{hcov}^{-}}$-II $\mathrm{CD}^{+} \mathrm{T}$ cell responses. Frequencies of $\mathrm{CD} 4 \mathrm{OL}^{+} 4-1 \mathrm{BB}^{+} \mathrm{CD}^{+}{ }^{+} \mathrm{T}$ cells after stimulation with S-II peptide pools of SARS-CoV-2 ( $y$ axis) and S-II peptide pools of hCoVs ( $x$ axis) 229E (light grey, $n=12$ ) and OC43 (dark grey, $n=9$ ) from RHDs are shown. $\mathbf{i}$, Schematic summary of the generation of SARS-CoV-2S-II-reactive $\mathrm{CD}^{+} \mathrm{T}$ cell lines. PBMC, peripheral blood mononuclear cells. $\mathbf{j}$, Enriched and expanded SARS-CoV-2S-II-reactive $\mathrm{CD}_{4}^{+} \mathrm{T}$ cells were restimulated with the indicated S-I and S-II peptide pools of SARS-CoV-2 and the two hCoV strains. SEB, staphylococcal enterotoxin B.d, f, g, Significance was calculated using two-tailed Mann-Whitney $U$-tests. $\mathbf{h}$, The correlation coefficient $r$ was calculated using a bivariate Pearson correlation and the related $P$ value was based on a $t$-distribution. to hCoVs. We therefore tested 18 out of the 68 HDs for the presence of antibodies that are specific for the four endemic hCoVs. We detected IgG antibodies against all four hCoVs in all tested HDs, regardless of the presence of measurable S-reactive $\mathrm{CD}^{+}{ }^{+} \mathrm{T}$ cells (Extended Data Fig. 6a). Frequencies of S-reactive or -cross-reactive $\mathrm{CD} 4^{+} \mathrm{T}$ cells in RHDs did not correlate with antibody levels against hCoVs, which potentially indicates that these antibodies have not been generated very recently. Similar findings have been obtained for other anti-viral CD4 ${ }^{+} \mathrm{T}$ cell responses, for example, after yellow fever vaccination (YFV-17D). CD4 ${ }^{+}$ T cell responses showed a significant correlation with the later generation of high titres of neutralizing antibodies only at very early time points after YFV-17D vaccination ${ }^{23}$.

We next determined whether SARS-CoV-2 S-reactive $C D 4^{+} \mathrm{T}$ cells in RHDs correlated with a $C D 4^{+} \mathrm{T}$ cell response to the $S$ protein of endemic $\mathrm{hCoVs}\left(\mathrm{S}_{\mathrm{hCov}}\right)$. To this end, peripheral blood mononuclear cells from HDs and RHDs were stimulated with S-I and S-II pools from SARS-CoV-2 and $\mathrm{S}_{\mathrm{hCov}}{ }^{-I}$ and $\mathrm{S}_{\mathrm{hCov}}$-II pools of OC43 and 229E (Fig. 2h and Extended Data
Fig. $6 \mathrm{~b}-\mathrm{d})$. There was a strong positive correlation of $\mathrm{CD} 4^{+} \mathrm{T}$ cell reactivity against S-II and $\mathrm{S}_{\mathrm{hCov}}-\mathrm{II}$ of OC43 and 229E ( $r=0.629$ and $r=0.715$, respectively) (Fig. 2h), whereas no or only a weak negative correlation was detected between S-I reactivity and reactivity towards $\mathrm{S}_{\mathrm{hCov}}-\mathrm{I}$ of OC43 and 229E ( $r=0.037$ and $r=-0.259$, respectively) (Extended Data Fig. 6b). No correlation was observed between reactivity to S-I or S-II and CMVpp65 (Extended Data Fig. 6c, d).

We next tested whether the S-reactive $\mathrm{CD} 4{ }^{+} \mathrm{T}$ cells of RHDs responded to stimulation with $\mathrm{S}_{\mathrm{hCov}}$. To this end, $\mathrm{S}$-II-reactive $\mathrm{CD} 4^{+} \mathrm{T}$ cells were isolated from three RHDs (RHD01, RHD07 and RHD15), expanded ex vivo for 12 days and subsequently restimulated with $\mathrm{S}_{\mathrm{hCov}}{ }^{-I}$ and $\mathrm{S}_{\mathrm{hCov}}-\mathrm{II}$ of OC43 and 229E, with the S-II pool as positive control, or with S-I and a peptide pool from CMVpp65 as negative controls (Fig. 2i,j). Restimulation with the SARS-CoV-2 S-II peptide pool induced the highest frequencies of $4-1 \mathrm{BB}^{+} \mathrm{CD} 4 \mathrm{OL}^{+} \mathrm{CD}^{+} \mathrm{T}$ cells, whereas negligible responses were measured in the negative controls (S-I, CMVpp65 and unstimulated groups), demonstrating the high specificity of the 
established S-II-reactive $\mathrm{CD}^{+}{ }^{+} \mathrm{T}$ cell lines (Fig. $2 \mathrm{j}$ ). By contrast, strong responses were observed against the $\mathrm{S}_{\mathrm{hCov}}$-II peptide pools of the two hCoVs (Fig. 2j). These findings provide evidence of the cross-reactivity of SARS-CoV-2 S-II-reactive cells to $\mathrm{S}_{\mathrm{hCov}}$ in the tested RHDs, suggesting that pre-existence of SARS-CoV-2-reactive T cells in seronegative SARS-CoV-2-naive individuals originates from previous immune responses to endemic hCoVs.

\section{Activation signatures in patients with COVID-19}

Finally, we assessed additional activation marker profiles on S-reactive T cells from patients with COVID-19 and RHDs. Expression of CD38, HLA-DR and Ki-67 has previously been shown to reliably characterize recently in vivo activated human $T$ cells during acute and chronic infections ${ }^{24-28}$. Notably, S-reactive $\mathrm{CD}^{+} \mathrm{T}$ cells from patients largely expressed CD38, HLA-DR and Ki-67 (Fig. 3a-d). Most S-reactive T cells in patients co-expressed CD38 and HLA-DR (Fig. 3e), which is characteristic of effector T cell responses during acute viral infections ${ }^{24,26}$, whereas CD38 and Ki-67 co-expression was more variable (Fig. 3f). By contrast, S-reactive $\mathrm{CD} 4^{+} \mathrm{T}$ cells from RHDs did not express CD38, HLA-DR and Ki-67, or only at low frequencies (Fig. 3b-f), and co-expression was not observed (Fig. 3e, f). In patients, considerable proportions of the entire peripheral CD4 ${ }^{+}$ and $\mathrm{CD}^{+} \mathrm{T}$ cell populations co-expressed CD38 and HLA-DR (data not shown); however, these cells could not be re-activated with our $S$ peptide pools in vitro. These findings are consistent with results of a recent study that showed refractory $T$ cell signatures in patients with

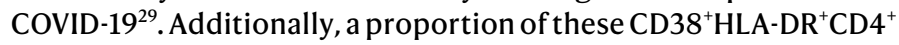
T cells probably targets other structural proteins of SARS-CoV-2. We furthermore show that the presence of S-reactive $\mathrm{CD} 4^{+} \mathrm{T}$ cells and, in particular, of CD38-expressing cells among S-reactive CD4 ${ }^{+} \mathrm{T}$ cells was highly variable among patients during the course of COVID-19 disease (Fig. 3g, h).

\section{Discussion}

Our study shows that S-reactive $\mathrm{CD} 4^{+} \mathrm{T}$ cells are present in patients with COVID-19 and in a considerable proportion of SARS-CoV-2-unexposed HDs. In light of the recent emergence of SARS-CoV-2, our data raise the possibility that such pre-existing S-reactive T cells represent cross-reactive clones that were probably acquired during previous infections with endemic hCoVs. hCoVs account for approximately $20 \%$ of 'common cold' upper respiratory tract infections and are ubiquitous, although they display winter seasonality ${ }^{30-32}$. On the basis of epidemiological data, it may be extrapolated that adults contract an hCoV infection, on average, every two to three years. Protective antibodies may wane mid-term but cellular immunity could remain ${ }^{10,13}$. Although the overall homology of the amino acid sequences of the $S$ protein is relatively low compared with spike glycoproteins from hCoVs, there is an overlap in MHC-II epitopes especially in the $\mathrm{C}$-terminal domain of the peptide pools used here (Fig. 1a and Extended Data Fig. 1). This may explain the preferential reactivity of $\mathrm{CD} 4^{+} \mathrm{T}$ cells to the $\mathrm{C}$-terminal domain in one third of HDs.

The biological role of pre-existing S-cross-reactive $\mathrm{CD} 4{ }^{+} \mathrm{T}$ cells in $35 \%$ of HDs remains unclear. However, assuming that these cells have a protective role in SARS-CoV-2 infection, they may contribute to our understanding of the divergent manifestations of COVID-19, and the notable resilience of children and young adults to symptomatic SARS-CoV-2 infection. Young adults and, especially, children in day-care centres have more frequent social contacts than elderly individuals, and this may therefore lead to a higher hCoV prevalence. This hypothesis requires further investigation in future longitudinal studies that assess the presence of pre-existing SARS-CoV-2-cross-reactive $\mathrm{CD}^{+} \mathrm{T}$ cells and their influence on the susceptibility to SARS-CoV-2 infection and age-related clinical outcomes of COVID-19.
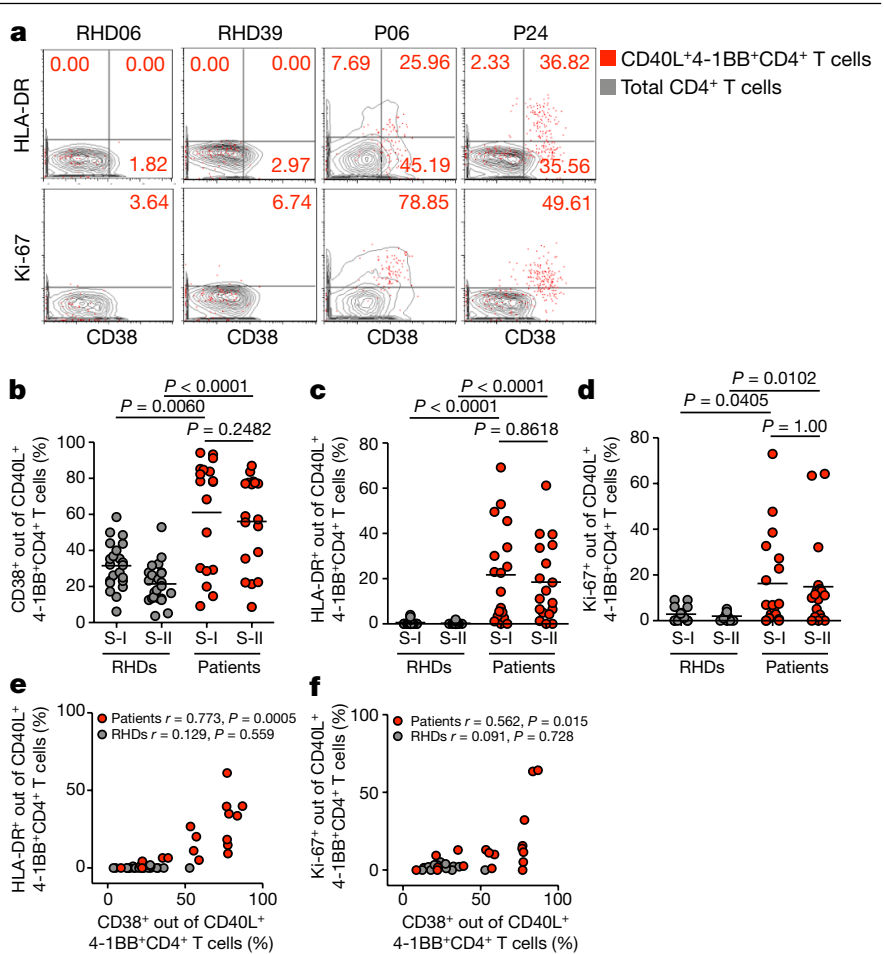

g
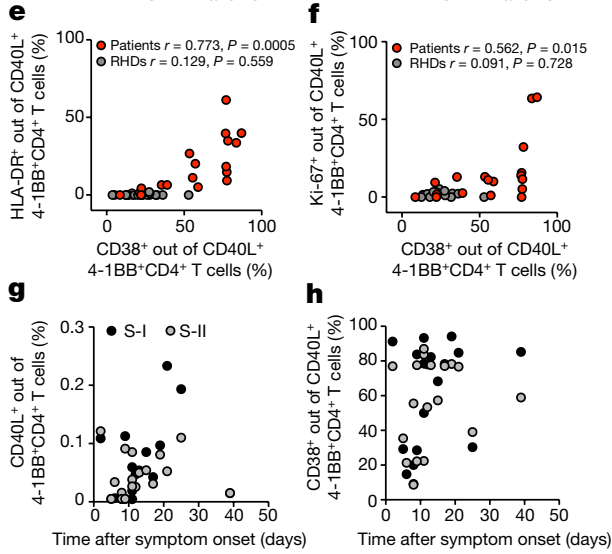

Fig. 3 | CD38, HLA-DR and Ki-67 expression in SARS-CoV-2 S-I-reactive and S-II-reactive $\mathrm{CD}^{+}{ }^{+} \mathrm{T}$ cells discriminates patients with COVID-19 from RHDs. a, Representative examples of HLA-DR and Ki-67 expression plotted against CD38 expression for S-II-reactive CD4 ${ }^{+} \mathrm{T}$ cells (red dots) compared with total $\mathrm{CD} 4^{+} \mathrm{T}$ cells (grey contours) in RHDs and patients with COVID-19. b-d, Comparison of frequencies of $\mathrm{CD} 38^{+}, \mathrm{HLA}-\mathrm{DR}^{+}$and $\mathrm{Ki}-67^{+}$cells among S-I-reactive and S-IIreactive $C D 4^{+} \mathrm{T}$ cells in $\mathrm{RHDs}(\mathbf{b}, \mathbf{c}, n=23 ; \mathbf{d}, n=17)$ and patients $(n=18)$. Significance was calculated using two-tailed Mann-Whitney $U$-tests.e,f, Co-expression of HLA-DR or Ki-67 and CD38 among S-II-reactive CD4 ${ }^{+} \mathrm{T}$ cells from RHDs $(\mathbf{e}, n=23$; f, $n=17)$ and patients $(n=18)$. The correlation coefficient $r$ was calculated using a bivariate Pearson correlation and the related $P$ value was based on a $t$-distribution. $\mathbf{g}, \mathbf{h}$, Frequencies of S-I-reactive and S-II-reactive CD40L ${ }^{+} 4$ $1 \mathrm{BB}^{+} \mathrm{CD} 4^{+} \mathrm{T}$ cells $(\mathbf{g})$ or $\mathrm{CD} 38^{+}$among S-II-reactive $\mathrm{CD} 4^{+} \mathrm{T}$ cells $(\mathbf{h})$ of patients $(n=18)$ plotted against time after symptom onset (days).

SARS-CoV-neutralizing antibodies are associated with convalescence, and they have been detected 12 months after disease 9 . However, the durability of neutralizing antibody responses against SARS-CoV-2 remains unknown. Although antibodies against hCoV can wane within months after infection, hCoV reinfection is accompanied by low-level and short-lived virus shedding with only mild symptoms of short duration, which indicates humoral-independent residual immunity ${ }^{10}$. Cellular immunity has not yet been studied in this context. In mouse models, however, $\mathrm{CD}^{+}$as well as $\mathrm{CD}^{+} \mathrm{T}$ cell responses directed against structural proteins such as the spike or nucleocapsid proteins of SARS-CoV critically contributed to viral clearance ${ }^{15,33,34}$. Understanding the extent to which and how SARS-CoV-2-specific humoral or cellular immunity mediates durable protection against reinfection is of critical importance in the coming months.

Our study reveals pre-existing cellular SARS-CoV-2 cross-reactivity in a substantial proportion of SARS-CoV-2-seronegative HDs. This finding could have considerable epidemiological implications regarding 


\section{Article}

herd immunity thresholds and projections for the COVID-19 pandemic. Our results provide a decisive rationale to initiate worldwide prospective studies to assess the contribution of pre-existing, potentially region-dependent, SARS-CoV-2-cross-reactive immunity to the diverse clinical outcomes of SARS-CoV-2 infection. Together with currently introduced serological tests, the data generated by such studies may critically inform evidence-based risk evaluation, patient monitoring, adaptation of containment methods and vaccine development.

\section{Online content}

Any methods, additional references, Nature Research reporting summaries, source data, extended data, supplementary information, acknowledgements, peer review information; details of author contributions and competing interests; and statements of data and code availability are available at https://doi.org/10.1038/s41586-020-2598-9.

1. Dong, E., Du, H. \& Gardner, L. An interactive web-based dashboard to track COVID-19 in real time. Lancet Infect. Dis. 20, 533-534 (2020).

2. Wang, D. et al. Clinical characteristics of 138 hospitalized patients with 2019 novel coronavirus-infected pneumonia in Wuhan, China. J. Am. Med. Assoc. 323, 1061-1069 (2020).

3. Corman, V. M. et al. Detection of 2019 novel coronavirus (2019-nCoV) by real-time RT-PCR. Euro Surveill. 25, 2000045 (2020).

4. Loeffelholz, M. J. \& Tang, Y.-W. Laboratory diagnosis of emerging human coronavirus infections - the state of the art. Emerg. Microbes Infect. 9, 747-756 (2020).

5. Wölfel, R. et al. Virological assessment of hospitalized patients with COVID-2019. Nature 581, 465-469 (2020)

6. Wu, J. T., Leung, K. \& Leung, G. M. Nowcasting and forecasting the potential domestic and international spread of the 2019-nCoV outbreak originating in Wuhan, China: a modelling study. Lancet 395, 689-697 (2020).

7. Amanat, F. et al. A serological assay to detect SARS-CoV-2 seroconversion in humans. Nat. Med. 26, 1033-1036 (2020).

8. Okba, N. M. A. et al. Severe acute respiratory syndrome coronavirus 2-specific antibody responses in coronavirus disease patients. Emerg. Infect. Dis. 26, 1478-1488 (2020).

9. Li, C. K. et al. T cell responses to whole SARS coronavirus in humans. J. Immunol. 181, 5490-5500 (2008)

10. Callow, K. A., Parry, H. F., Sergeant, M. \& Tyrrell, D. A. J. The time course of the immune response to experimental coronavirus infection of man. Epidemiol. Infect. 105, 435-446 (1990).

11. Libraty, D. H., O'Neil, K. M., Baker, L. M., Acosta, L. P. \& Olveda, R. M. Human CD4 ${ }^{+}$memory T-lymphocyte responses to SARS coronavirus infection. Virology 368, 317-321 (2007).

12. Yang, J et al Searching immunodominant epitopes prior to epidemic: HLA class II-restricted SARS-CoV spike protein epitopes in unexposed individuals. Int. Immunol. 21, 63-71 (2009).

13. $\mathrm{Ng}, \mathrm{O}$. W. et al. Memory T cell responses targeting the SARS coronavirus persist up to 11 years post-infection. Vaccine 34, 2008-2014 (2016).

14. Mitchison, N. A. T-cell-B-cell cooperation. Nat. Rev. Immunol. 4, 308-312 (2004).
15. Yang, Z. Y. et al. A DNA vaccine induces SARS coronavirus neutralization and protective immunity in mice. Nature 428, 561-564 (2004).

16. Zhu, Z. et al. Potent cross-reactive neutralization of SARS coronavirus isolates by human monoclonal antibodies. Proc. Natl Acad. Sci. USA 104, 12123-12128 (2007).

17. Ju, B. et al. Human neutralizing antibodies elicited by SARS-CoV-2 infection. Nature $\mathbf{5 8 4}$, $115-119$ (2020).

18. Meng, T. et al. The insert sequence in SARS-CoV-2 enhances spike protein cleavage by TMPRSS. Preprint at https://www.biorxiv.org/content/10.1101/2020.02.08.926006v3 (2020).

19. Walls, A. C. et al. Structure, function, and antigenicity of the SARS-CoV-2 spike glycoprotein. Cell 181, 281-292 (2020)

20. Frentsch, $\mathrm{M}$. et al. Direct access to $\mathrm{CD} 4^{+} \mathrm{T}$ cells specific for defined antigens according to CD154 expression. Nat. Med. 11, 1118-1124 (2005).

21. Sattler, A. et al. Cytokine-induced human IFN- $\mathrm{Y}$-secreting effector-memory Th cells in chronic autoimmune inflammation. Blood 113, 1948-1956 (2009).

22. Schoenbrunn, A. et al. A converse 4-1BB and CD40 ligand expression pattern delineates activated regulatory $T$ cells (Treg) and conventional T cells enabling direct isolation of alloantigen-reactive natural Foxp3 ${ }^{+}$Treg. J. Immunol. 189, 5985-5994 (2012).

23. Kohler, S. et al. The early cellular signatures of protective immunity induced by live viral vaccination. Eur. J. Immunol. 42, 2363-2373 (2012).

24. Appay, V. et al. Memory CD8 ${ }^{+} \mathrm{T}$ cells vary in differentiation phenotype in different persistent virus infections. Nat. Med. 8, 379-385 (2002).

25. Blom, K. et al. Temporal dynamics of the primary human T cell response to yellow fever virus $17 \mathrm{D}$ as it matures from an effector- to a memory-type response. J. Immunol. 190, 2150-2158 (2013).

26. Callan, M. F. C. et al. Direct visualization of antigen-specific $C D 8^{+} T$ cells during the primary immune response to Epstein-Barr virus in vivo. J. Exp. Med. 187, 1395-1402 (1998).

27. Miller, J. D. et al. Human effector and memory $C D 8^{+} T$ cell responses to smallpox and yellow fever vaccines. Immunity 28, 710-722 (2008).

28. Schulz, A. R. et al. Low thymic activity and dendritic cell numbers are associated with the immune response to primary viral infection in elderly humans. J. Immunol. 195 4699-4711 (2015).

29. Diao, B. et al. Reduction and functional exhaustion of $\mathrm{T}$ cells in patients with coronavirus disease 2019 (COVID-19). Front. Immunol. 11, 827 (2020).

30. Tyrrell, D. A. J. Common Colds and Related Diseases (E. Arnold, 1965).

31. Lidwell, O. M. \& Williams, R. E. The epidemiology of the common cold. I. J. Hyg. 59, 309-319 (1961).

32. Gaunt, E. R., Hardie, A., Claas, E. C. J., Simmonds, P. \& Templeton, K. E. Epidemiology and clinical presentations of the four human coronaviruses 229E, HKU1, NL63, and OC43 detected over 3 years using a novel multiplex real-time PCR method. J. Clin. Microbiol. 48, 2940-2947 (2010).

33. Channappanavar, R., Fett, C., Zhao, J., Meyerholz, D. K. \& Perlman, S. Virus-specific memory CD8 T cells provide substantial protection from lethal severe acute respiratory syndrome coronavirus infection. J. Virol. 88, 11034-11044 (2014).

34. Wang, B. et al. Identification of an $\mathrm{HLA}-\mathrm{A}^{*} \mathrm{O} 201$-restricted $\mathrm{CD} 8^{+} \mathrm{T}$-cell epitope SSp-1 of SARS-CoV spike protein. Blood 104, 200-206 (2004)

Publisher's note Springer Nature remains neutral with regard to jurisdictional claims in published maps and institutional affiliations.

(c) The Author(s), under exclusive licence to Springer Nature Limited 2020 


\section{Methods}

\section{Data reporting}

No statistical methods were used to predetermine sample size. The experiments were not randomized and the investigators were not blinded to allocation during experiments and outcome assessment.

\section{Study participants}

The study was approved by the Institutional Review Board of the Charite (EA2/066/20). After providing written informed consent, 68 HDs (Table 1 and Extended Data Table 3) and 18 and 7 additional patients with COVID-19 (Table 1 and Extended Data Table 2, 4) were included in the study. Patients with COVID-19 who tested positive for SARS-CoV-2 RNA in nasopharyngeal swabs were recruited at Charité Campus Virchow-Klinikum, Berlin, between 1 March and 2 April 2020. All patients with COVID-19 were enrolled in the Berlin prospective observation COVID-19 study (PA-COVID-19) ${ }^{35}$. Disease severity was grouped on the basis of the requirement for supplementary oxygen or ventilation (mild, hospitalized, no supplementary oxygen; severe, hospitalized, supplementary oxygen (including high-flow oxygen); critical, hospitalized, invasive ventilation). For intracellular cytokine and memory T cell staining, seven additional patients with COVID-19 (Extended Data Table 4) were enrolled at later time points and five RHDs were re-recruited. To retrospectively validate SARS-CoV-2 seronegativity, all HDs were re-invited between 4 and 7 May 2020 for re-assessment of anti-S1 IgG titres. In total, 65 out of $68 \mathrm{HDs}$ could be re-recruited and all HDs were seronegative for SARS-CoV-2 (Extended Data Fig. 4).

\section{Serology}

Anti-SARS-CoV-2 IgG ELISA was performed using a commercial kit (EUROIMMUN) as described and validated previously ${ }^{8}$. Recombinant immunofluorescence assays to determine IgG titres against hCoV were performed using VeroB4 cells that expressed cloned recombinant spike proteins from hCoV-229E, hCoV-NL63, hCoV-OC43 and hCoV-HKU1, as previously described ${ }^{36}$.

\section{Cell isolation and stimulation}

Peripheral blood mononuclear cells were isolated from heparinized whole blood by density gradient centrifugation according to manufacturer's instructions (Leucosep tubes, Greiner; Biocoll, Bio\&SELL). Stimulation was performed with $5 \times 10^{6}$ peripheral blood mononuclear cells in RPMI 1640 medium (Gibco) supplemented with $10 \%$ heat-inactivated $A B$ serum (Pan Biotech), $100 \mathrm{U} / \mathrm{ml}$ penicillin (Biochrom), $0.1 \mathrm{mg} / \mathrm{ml}$ streptomycin (Biochrom) and PepMix SARS-CoV-2 spike glycoprotein (JPT) peptide pool 1 or 2 in the presence of $1 \mu \mathrm{g} / \mathrm{ml}$ purified anti-CD28 antibody (clone CD28.2, BD Biosciences). The PepMix SARS-CoV-2 spike glycoprotein pool 1 covering the $\mathrm{N}$-terminal amino acid residues $1-643$ (abbreviated to 'S-I' (N-term)) contained 15815 -mers that overlapped by 11 amino acids. PepMix SARS-CoV-2 spike glycoprotein pool 2 covered the C-terminal amino acid residues 633-1273 (abbreviated to 'S-II' (C-term)) contained 15615-mers that overlapped by 11 amino acids and one 17-mer at the $C$ terminus, that is, 157 peptides in total. Both peptide pools were used at $1 \mu \mathrm{g} / \mathrm{ml}$ per peptide. Further details on the peptide pools and predicted MHC-II epitopes are provided in Fig. 1, Extended Data Fig. 1 and Extended Data Table 1. Stimulation controls were performed with equal concentrations of DMSO in PBS (unstimulated) or $1.5 \mathrm{mg} \mathrm{SEB} / 1.0 \mathrm{mg}$ TSST1 (Sigma-Aldrich) and PepMix HCMVA (pp65) (>90\%; CMVpp65) (JPT) in the presence of $1 \mu \mathrm{g} / \mathrm{ml}$ purified anti-CD28 antibody (clone CD28.2, BD Biosciences) as positive controls. Incubation was performed at $37^{\circ} \mathrm{C}, 5 \%$ $\mathrm{CO}_{2}$ for $16 \mathrm{~h}$ with $10 \mu \mathrm{g} / \mathrm{ml}$ brefeldin A (Sigma-Aldrich) added after $2 \mathrm{~h}$. Stimulation was stopped by incubation in $2 \mathrm{mMEDTA}$ for $5 \mathrm{~min}$. Stimulation with hCoV spike glycoprotein $\left(\mathrm{S}_{\mathrm{hCov}}\right)$ peptide pools was performed using the conditions described above but with $1 \mu \mathrm{g} / \mathrm{ml}$ per peptide of the following peptide pools: PepMix hCoV-229E spike glycoprotein pool 1 or 2 or PepMix hCoV-OC43 spike glycoprotein pool 1 or 2 (allJPT).

\section{Flow cytometry}

After stimulation, staining of surface antigens was carried out for $15 \mathrm{~min}$ with the following fluorochrome-conjugated antibodies titrated to their optimal concentrations: CD38-PE-Vio770 (clone REA671, Miltenyi, 1:400), CD69-APC-Cy7 (FN50, BioLegend, 1:100), HLAD-DR-VioGreen (REA805, Miltenyi, 1:50), CD4-BrilliantViolet605(RPA-T4, BioLegend, 1:200), CD8-PerCP (SK1, BioLegend, 1:100) with $1 \mathrm{mg} / \mathrm{ml}$ beriglobin (CSL Behring) added before the staining. To exclude dead cells, Zombie Yellow fixable viability staining (BioLegend) was added for the last 10 min of incubation. Fixation and permeabilization were performed with eBioscience FoxP3 fixation and PermBuffer (Invitrogen) according to the manufacturer's protocol and intracellular staining was carried out for $30 \mathrm{~min}$ in the dark at room temperature with beriglobin added before staining with 4-1BB-PE (4-1BB is also known as CD137; clone 4B4-1, BD, 1:10), CD40L-APC (CD40L is also known as $\mathrm{CD} 154 ; 5 \mathrm{C} 8$, Miltenyi, 1:40), IFN $\gamma$-AlexaFluor700 (B27, BD, 1:50), TNF-PacificBlue (MAb11, BioLegend, 1:100) and Ki-67-AlexaFluor488 (B56, BD, 1:100). To assess naive/memory T cell phenotypes and cytokine expression, the following antibodies were used: surface staining was performed with CD3-V500 (SP34-2, BD, 1:50), CD8-PerCP(SK1, BioLegend, 1:100), CD4-BrilliantViolet605 (RPA-T4, BioLegend, 1:200), CCR7-AlexaFluor488 (G043H7, BioLegend, 1:150), CD45RA-PE-Cy7 (HI100, BioLegend, 1:200). IFN $\gamma$-AlexaFluor700 (B27, BD, 1:100), CD40L-BrilliantViolet421 (24-31, BioLegend, 1:200), IL-2-APC (5344.111, BD, 1:200), 4-1BB-PE (4B4-1, BD, 1:10) and IL-17A-APC-Cy7 (BL168, BioLegend, 1:20) were used for intracellular staining after fixation and permeabilization using BD FACSLysing Buffer and BD Perm2 Buffer, according to the manufacturer's instructions. Samples were measured on a MACSQuant Analyzer 16 using MACSQuantify software (v.2.13). Instrument performance was monitored daily with Rainbow Calibration Particles (BD).

\section{Cell enrichment, expansion and restimulation}

S-II-reactive T cells were enriched by magnetic cell sorting (MACS) from peripheral blood mononuclear cells stimulated with PepMix SARS-CoV-2 spike glycoprotein peptide pool2 (JPT) in the presence of $1 \mu \mathrm{g} / \mathrm{ml}$ purified anti-CD28 (clone CD28.2, BD Biosciences) and $1 \mu \mathrm{g} / \mathrm{ml}$ anti-CD40 (clone 5C3, BioLegend) antibodies. After stimulation for $16 \mathrm{~h}$, cells were stained with CD40L-APC and 4-1BB-PE and first enriched with anti-APC MultiSort MicroBeads (Miltenyi) according to the manufacturer's instructions. After the release of anti-APC-MicroBeads, a second enrichment was performed with anti-PE MicroBeads (Miltenyi). Purity was checked each time to $>80 \%$ of alive cells. Antigen presenting feeder cells were generated by CD3 MicroBead (Miltenyi) depletion of the CD40L-APC-negative fraction and subsequent inactivation by irradiation at $50 \mathrm{~Gy}$. The irradiated feeder cells were co-cultured with the enriched $4-1 \mathrm{BB}^{+} \mathrm{CD} 4 \mathrm{OL}^{+} \mathrm{T}$ cells at a ratio of $1: 1$ in RPMI 1640 medium (Gibco) supplemented with $10 \%$ heat-inactivated $A B$ serum (Pan Biotech), $100 \mathrm{U} / \mathrm{ml}$ penicillin (Biochrom), $0.1 \mathrm{mg} / \mathrm{ml}$ streptomycin (Biochrom) in the presence of $10 \mathrm{ng} / \mathrm{ml} \mathrm{IL-7} \mathrm{and} \mathrm{IL-15} \mathrm{(both} \mathrm{Miltenyi)}$ for 12 days followed by 2-day cytokine starvation before restimulation. Restimulation was carried with the conditions described above and additionally with $1 \mu \mathrm{g} / \mathrm{ml}$ per peptide of the following peptide pools: PepMix hCoV-229E spike glycoprotein pool 1 or 2 or PepMix hCoV-OC43 spike glycoprotein pool 1 or 2 (all JPT).

\section{Data analysis and statistics}

Sequence alignments were performed using R (v.3.6.1) including package Clustal $\mathrm{X}^{37}$ and using the Needlemann-Wunsch algorithm ${ }^{38}$. Flow cytometry data were analysed with FlowJo v.9.9.6 (FlowJo). Microsoft Excel (v.14.1.0) and Prism 5 and 8 (GraphPad) were used for plotting and statistical analysis. In stimulation experiments, frequencies of activated $\mathrm{CD} 4^{+} \mathrm{T}$ cells were background-subtracted, with the frequency in the unstimulated control sample representing the background. 


\section{Article}

Non-parametric testing was used to compare cell frequencies and antibody titres between groups (two-tailed Mann-Whitney $U$-test). $n$ indicates the number of donors.

\section{Reporting summary}

Further information on research design is available in the Nature Research Reporting Summary linked to this paper.

\section{Data availability}

All flow cytometry data are made available at www.FlowRepository. org (experiment ID: FR-FCM-Z2K3). The individual gating strategies for all donors are shown in Supplementary Information.

35. Kurth, F. et al. Studying the pathophysiology of coronavirus disease 2019: a protocol for the Berlin prospective COVID-19 patient cohort (Pa-COVID-19). Infection 48, 619-626 (2020).

36. Corman, V. M. et al. Assays for laboratory confirmation of novel human coronavirus (hCoV-EMC) infections. Euro Surveill. 17, 20334 (2012).

37. Larkin, M. A. et al. Clustal W and Clustal X version 2.0. Bioinformatics 23, 2947-2948 (2007).

38. Needleman, S. B. \& Wunsch, C. D. A general method applicable to the search for similarities in the amino acid sequence of two proteins. J. Mol. Biol. 48, 443-453 (1970).

Acknowledgements We thank U. Klein and H.-P. Herzel for discussion; T. Kaiser and J. Kirsch from the Flow Cytometry Core Facility (FCCF) of the DRFZ for technical help; and
B. Timmerman from the Sequencing Core Facility of the Max Planck Institute for Molecular Genetics for discussion. This work was supported by the German Research Foundation (KFO339 to J.B. and F.F., SFB-TR84 projects A4 and B6 to S.H., B8 to M.M., C6 to M.W., C8 and $\mathrm{C} 10$ to L.E.S., and C9 to M.W. and N.S.) and by the German Federal Ministry of Education and Research (BMBF-RAPID to S.H. and C.D., and CAPSyS to M.W. and N.S.). This work was additionally funded by the Federal Ministery of Health through a resolution of the German Bundestag to A.T., J.B., L.H. and M.D.

Author contributions J.B., L.L. and M.F. planned and performed experiments and analysed the data. D.W., P.G., J.R., M.D., B.K., F.F., E.B., M.M. and L.H. performed experiments. F. Kurth, A.H., S.H., K.B., I.D., M. A. Mall, S.V., M.W., N.S., C.D. and L.E.S. managed initial patient contacts, and designed and supervised clinical management and clinical data. M. A. Müller and V.M.C. planned and performed experiments and analysed the data. J.S. and S.M. established high-throughput analysis. R.L. designed experiments. F. Kern, U.R. and H.W. established new reagents. G.C.-T. and A.T. designed and supervised the study. C.G.-T., L.E.S. and A.T. wrote the manuscript.

Competing interests F. Kern, U.R. and H.W. are employed at JPT Peptide Technologies, who have provided peptide pools for this work. F. Kern also part-owns and is inventor on a patent describing the use of overlapping peptide pools for the stimulation of T cells. Until this patent expires, he will receive royalties on JPT PepMix sales. J.S. and S.M. are employed at Miltenyi Biotec, who provided reagents and devices for this study. All other authors declare no competing interests.

Additional information

Supplementary information is available for this paper at https://doi.org/10.1038/s41586-020 2598-9.

Correspondence and requests for materials should be addressed to C.G.-T., L.E.S. or A.T. Peer review information Nature thanks Akiko Iwasaki and the other, anonymous, reviewer(s) for their contribution to the peer review of this work. Peer reviewer reports are available.

Reprints and permissions information is available at http://www.nature.com/reprints. 

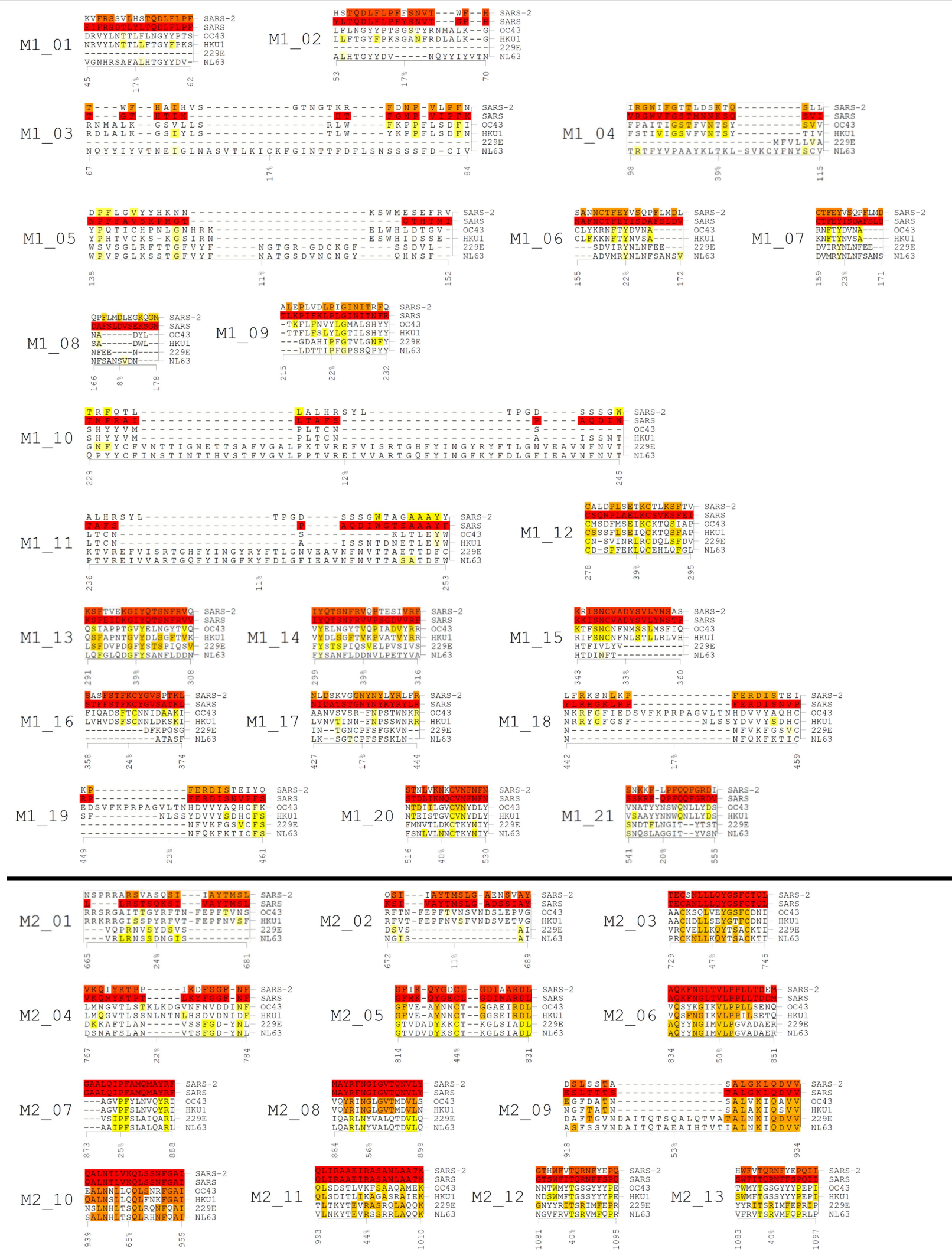

Extended Data Fig. 1 | Homology of reported MHC-II epitopes in the spike glycoprotein of SARS-CoV compared with SARS-CoV-2 and endemic hCoV strains. For each epitope, the respective section from a global sequence alignment between SARS-CoV, SARS-CoV-2 and the hCoVs NL63, 229E, HKU1 and $\mathrm{OC} 43$ is shown. Identical residues are colour-coded from white (no identity) to red (100\% identity). Reported MHC-II epitopes are described further in Extended Data Table 1. 


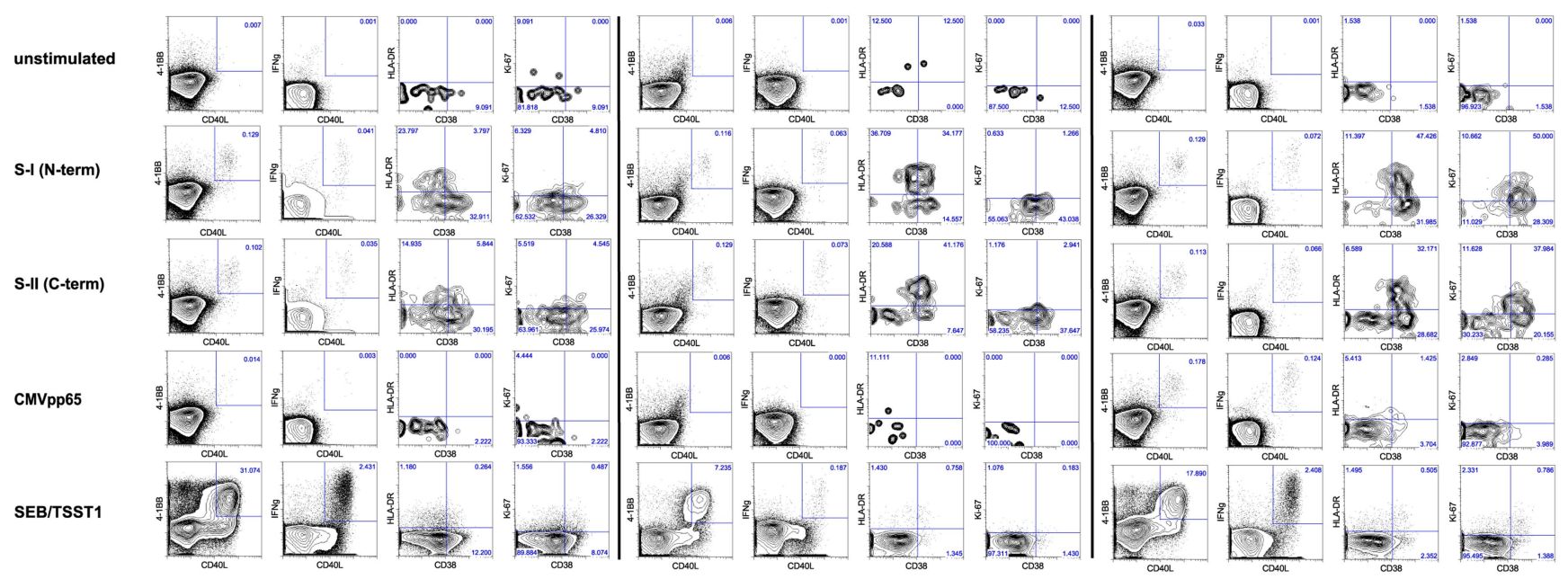

Reactive Healthy Donors

RHD15

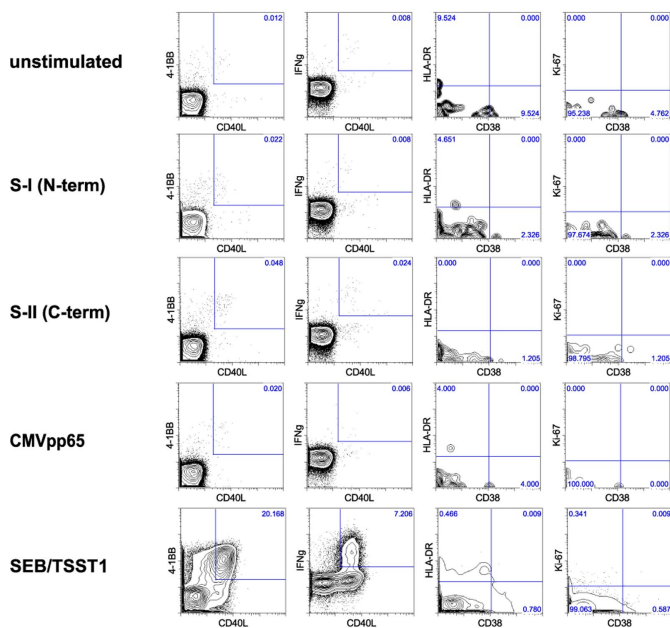

RHD21

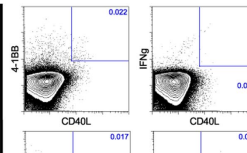

耪, (o)

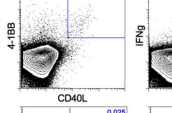

(D)

$\theta 0$

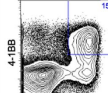

Jes?

部

Rat

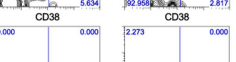

$\sum_{0038}$ in

(n)

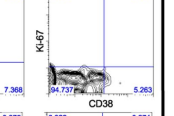

2

Healthy Donors

unstimulated

HD17

HD50

HD55

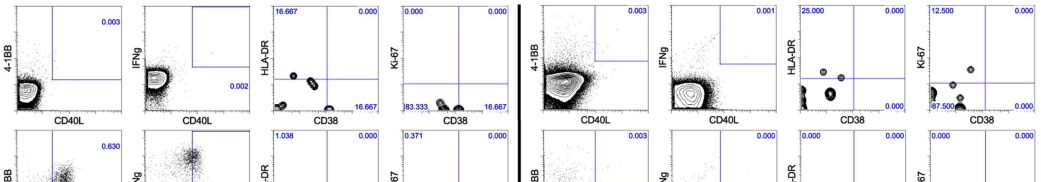

S-I (N-term)

$\mathrm{D}^{4} \mathrm{~B}^{2}$

$\frac{9}{5}$

D

S-II (C-term)<smiles>C=[Pb]</smiles>

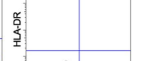

.<smiles>[C+]C=CC=C</smiles>
$\therefore 0$.

2

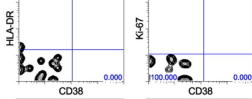

CMVpp65 $b_{\text {oxax }}$ ?

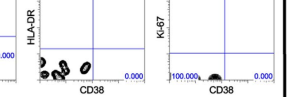

SEB/TSST1

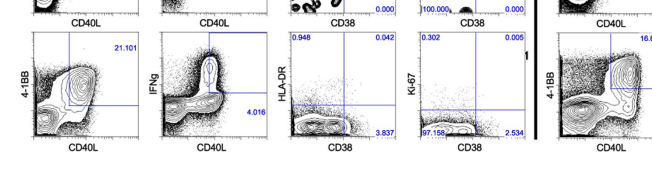

Extended Data Fig. 2 | Exemplary analyses gates and dot plots from patients with COVID-19, RHDs and HDs. FACS analysis was performed to determine the frequencies of S-I-reactive and S-II-reactive $\mathrm{CD}^{+}{ }^{+} \mathrm{T}$ cells and the ratios of $\mathrm{CD}^{2} 8^{+}, \mathrm{HLA}-\mathrm{DR}^{+}$and $\mathrm{Ki}-67^{+}$cells among the $\mathrm{S}$-I-reactive and S-II-reactive $\mathrm{CD}^{+} \mathrm{T}$ cells. 


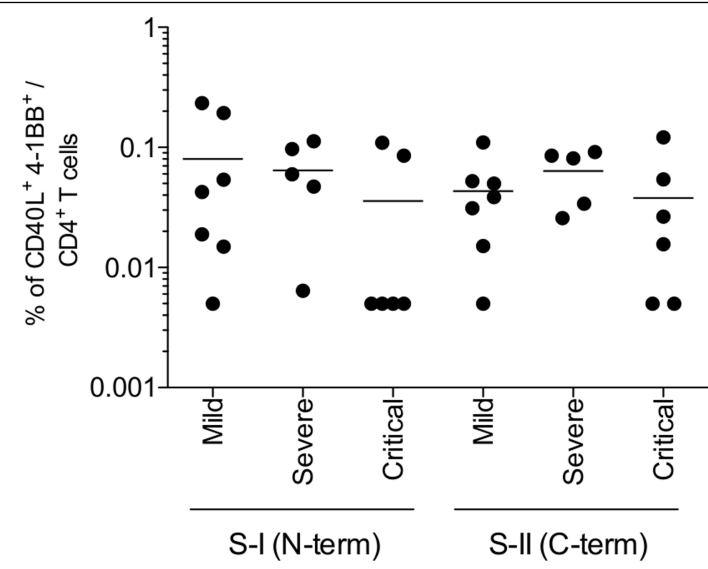

Extended Data Fig. 3 | Most S-I-non-reactive and S-II-non-reactive patients with COVID-19 had a critical disease stage. Frequencies of S-I- and S-II-reactive $\mathrm{CD} 4^{+} \mathrm{T}$ cells in patients with COVID-19 are grouped according to disease severity for patients with mild $(n=7)$, severe $(n=5)$ or critical $(n=6)$ disease. 


\section{Article}

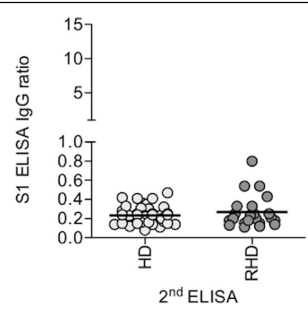

Extended Data Fig. 4 | Repeated serology of HDs confirms unexposed status of HDs and RHDs. SARS-CoV-2 S1 serology of HDs $(n=43)$ and RHDs $(n=22)$ more than 28 days after initial sampling. Anti-S1 IgG titres are expressed as a ratio normalized to the calibration well, which contained the provided control serum (as described in the manufacturing instructions). 


\section{a}
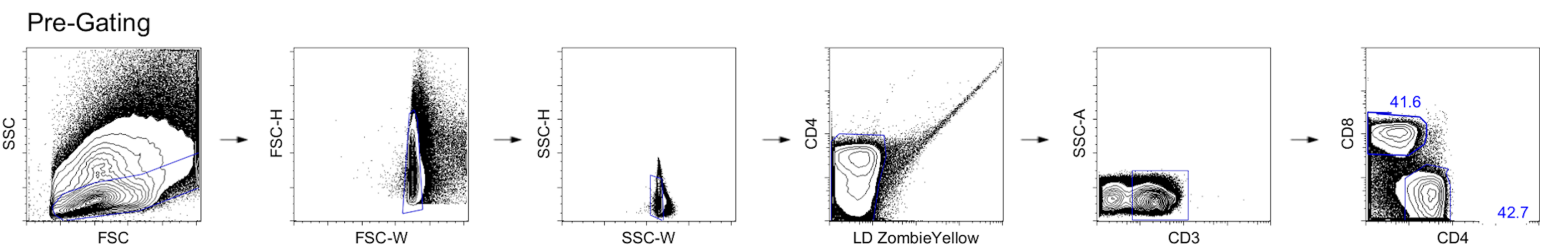

b
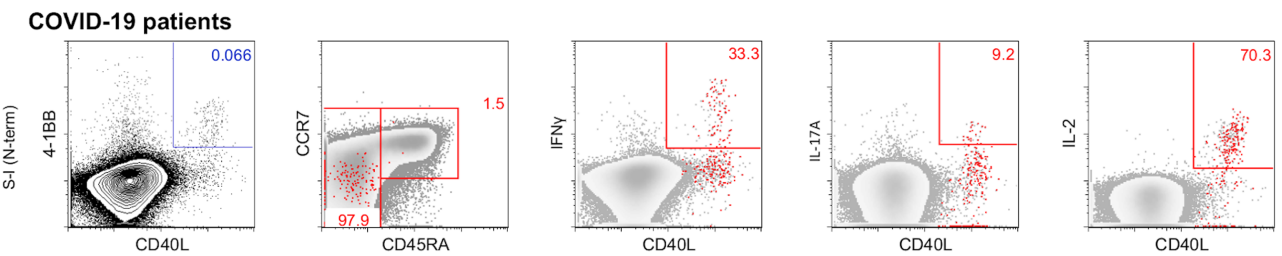

$\mathrm{CD} 40 \mathrm{~L}^{+} 4-1 \mathrm{BB}^{+} \mathrm{CD}^{+} \mathrm{T}$ cells
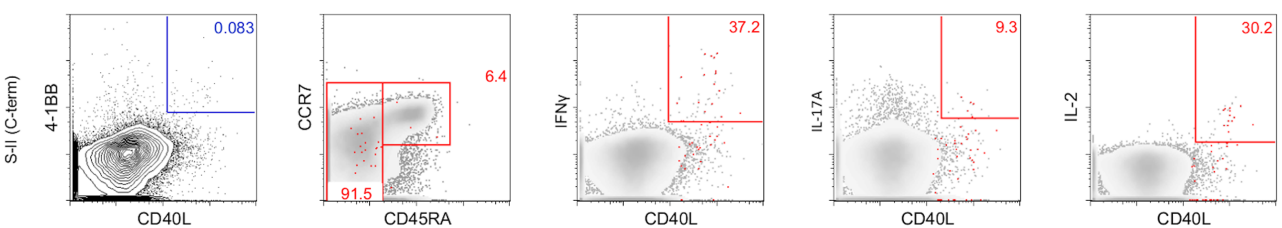

C
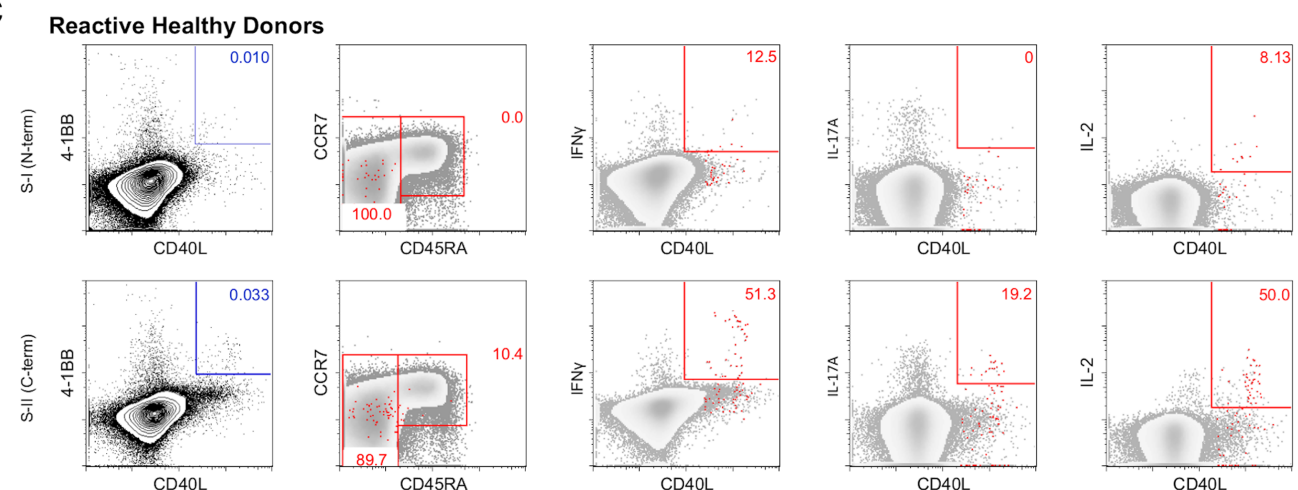

d

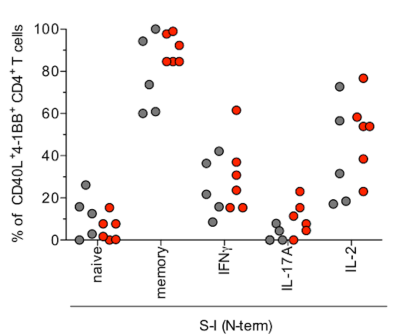

$\therefore \quad$ RHD
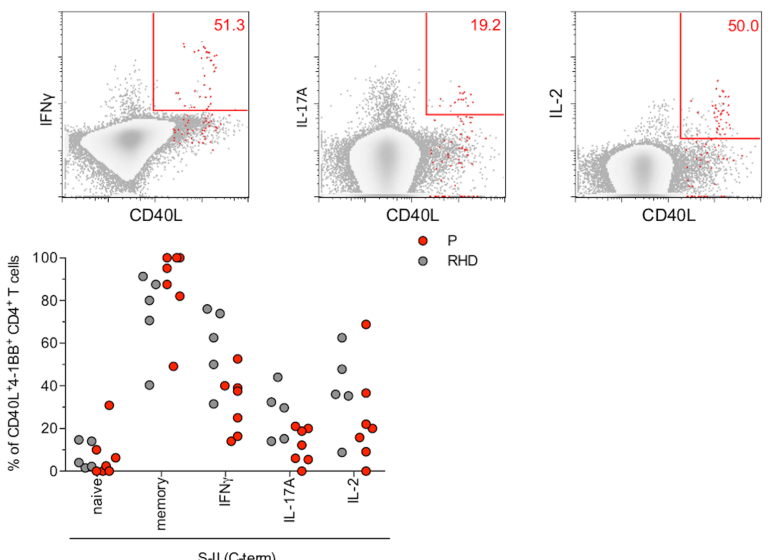

Reactive Healthy Donors

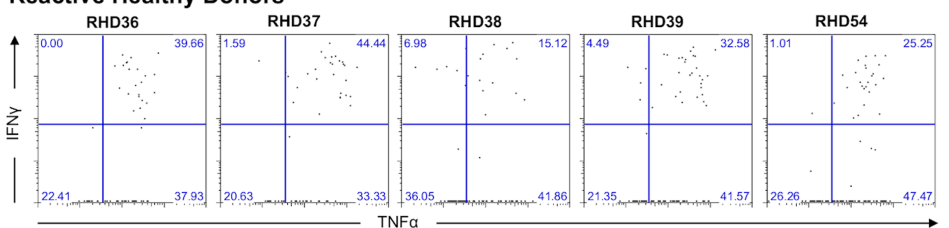

COVID-19 patients

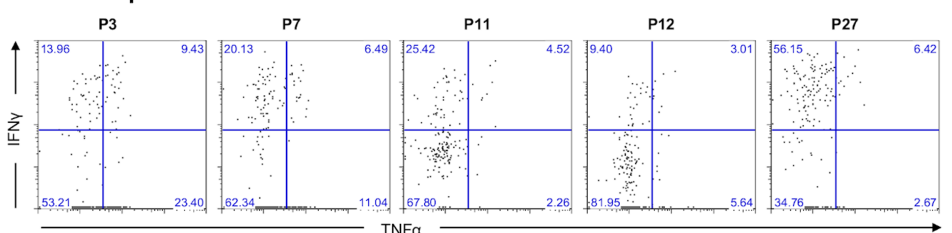

Extended Data Fig. 5 | Expression of cytokines and differentiation markers in S-I-reactive and S-II-reactive $\mathrm{CD} 40 \mathrm{~L}^{+} 4-\mathrm{BBB}^{+} \mathrm{CD}^{+} \mathrm{T}$ cells from patients with COVID-19 and RHDs.a, Gating schematic of one representative donor to select for $\mathrm{CD}^{+} \mathrm{CD}^{+} \mathrm{T}$ cells and exclude dead cells and doublets. b, c, Determination of the differentiation marker and cytokine profiles of S-Iand S-II-reactive CD4 ${ }^{+} \mathrm{T}$ cells shown for one patient with COVID-19 and one RHD after S-I and S-II peptide pool stimulation, respectively. SARS-CoV-2 S-reactive $\mathrm{CD} 4{ }^{+} \mathrm{T}$ cells were defined by CD40L and 4-1BB expression after stimulation and are displayed as red dots. Numbers are the frequencies of cytokine-expressing
S-I/S-II-reactive $\mathrm{CD}^{+}{ }^{+} \mathrm{T}$ cells and the distribution of the naive $\left(\mathrm{CCR}^{+} \mathrm{CD}^{-} 5 \mathrm{RA}^{+}\right)$ and memory $\left(\mathrm{CCR7}^{+} \mathrm{CD}^{2} 5 \mathrm{RA}^{-}\right.$or $\left.\mathrm{CCR} 7^{-} \mathrm{CD}^{2} 5 \mathrm{RA}^{-}\right)$phenotypes of S-I/S-II-reactive $\mathrm{CD} 4^{+} \mathrm{T}$ cells, respectively. $\mathrm{d}$, Diagrams summarizing the cytokine and differentiation marker distribution frequencies of S-I- and S-II-reactive CD4 T cells from patients with COVID-19 $(n=7)$ and RHDs $(n=5)$. e, Expression of TNF and IFN $\gamma$ in S-II-reactive CD4 ${ }^{+} \mathrm{T}$ cells from patients and RHDs. Five representative plots of TNF versus IFN $\gamma$ expression in $\mathrm{CD}^{2} 0 \mathrm{~L}^{+} 4-1 \mathrm{BB}^{+} \mathrm{CD}^{+}$ $\mathrm{T}$ cells from RHDs and patients with COVID-19; gating strategy as shown in Fig. 2. 


\section{Article}

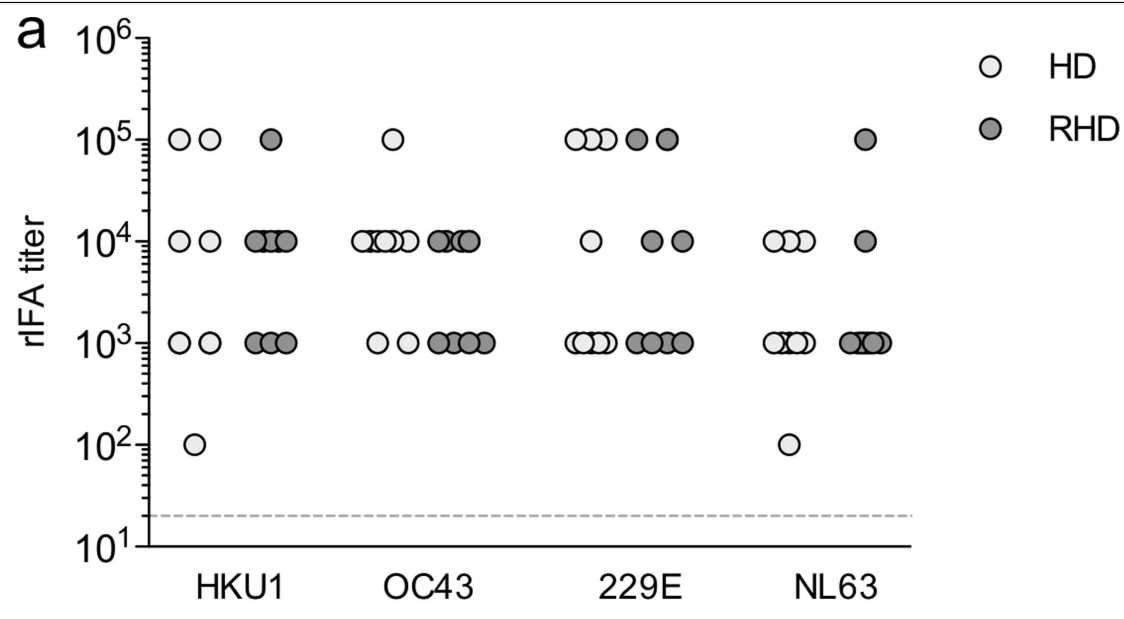

b

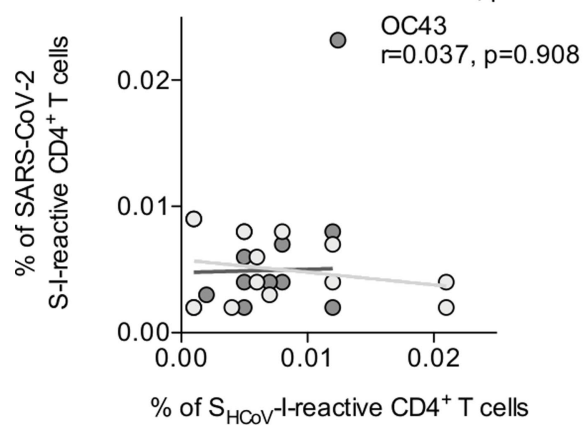

C

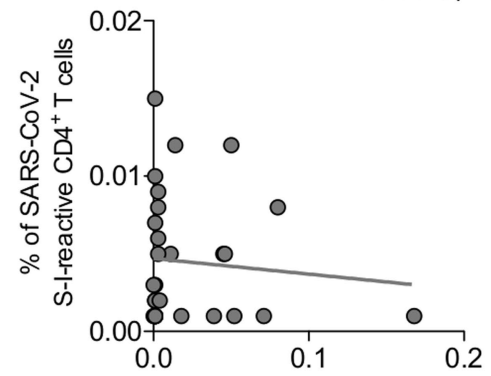

$\%$ of CMV-reactive $\mathrm{CD} 4^{+} \mathrm{T}$ cells
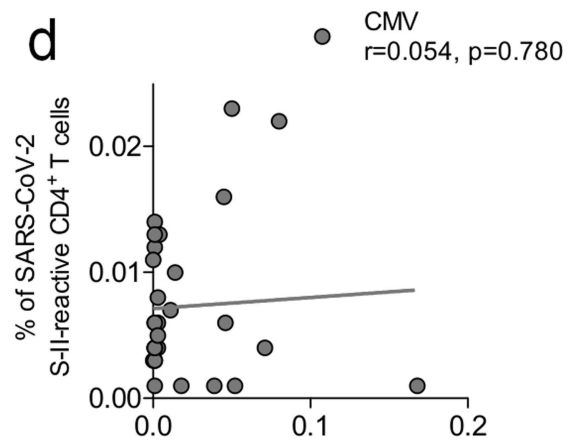

$\%$ of CMV-reactive $\mathrm{CD}^{+} \mathrm{T}$ cells
Extended Data Fig. 6 | hCoV-specific IgG antibody titres in HDs and RHDs and specificity of SARS-CoV-2-reactive T cells in HDs. a, IgG antibody titres against endemic coronavirus strains ( $\mathrm{hCoVs}$ ). VeroB4 cells expressing recombinant spike proteins of hCoV-HKU1, hCoV-OC43, hCoV-229E and hCoV-NL63 were used in a recombinant immunofluorescence assay (rIFA) as described previously ${ }^{36}$. Titres above 1:20 dilution were considered positive (indicated by the dashed line). HD, $n=9$; RHD, $n=9 . \mathbf{b}-\mathbf{d}$, Frequencies of SARS-CoV-2S-I-reactive CD4 ${ }^{+} \mathrm{T}$ cells in HDs do not correlate with frequencies of $\mathrm{S}_{\text {hcov }}$-I-reactive or CMV-reactive CD4 ${ }^{+} \mathrm{T}$ cells. Frequencies of SARS-CoV-2
S-II-reactive $\mathrm{CD}^{+} \mathrm{T}$ cells in HDs do not correlate with frequencies of CMV-reactive $\mathrm{CD}^{+} \mathrm{T}$ cells. b, Scatter plot of $\mathrm{S}_{\mathrm{hCov}} \mathrm{I}^{-\mathrm{I}-\text { reactive } \mathrm{CD} 4^{+} \mathrm{T} \text { cell }}$ frequencies (229E, $n=12$; OC43, $n=9$ ) and SARS-CoV-2 S-I-reactive CD4 ${ }^{+} \mathrm{T}$ cell frequencies. c, Scatter plot of SARS-CoV-2S-I-reactive $\mathrm{CD} 4^{+} \mathrm{T}$ cell and CMV-reactive $\mathrm{CD} 4^{+} \mathrm{T}$ cell frequencies $(n=21)$. d, Scat ter plot of SARS-CoV-2 $\mathrm{S}$-II-reactive $\mathrm{CD} 4^{+} \mathrm{T}$ cell and CMV-reactive $\mathrm{CD} 4^{+} \mathrm{T}$ cell frequencies $(n=21)$. b-d, Correlation coefficients $(r)$ were calculated by Pearson correlation and the related $P$ values are based on $t$-distributions. 
Extended Data Table 1 | Reported MHC-II epitopes in the spike glycoprotein of SARS-CoV

\begin{tabular}{|c|c|c|c|c|c|c|c|}
\hline ID & PepMix ${ }^{\top M}$ & Sequence & $\begin{array}{l}\text { Maximum } \\
\text { identity } \\
\text { common cold } \\
\text { viruses }(\%)\end{array}$ & $\begin{array}{l}\text { Identity } \\
\text { SARS-CoV-2 }\end{array}$ & $\begin{array}{c}\text { Start position } \\
\text { SARS }\end{array}$ & $\begin{array}{c}\text { Stop position } \\
\text { SARS }\end{array}$ & Reference \\
\hline M1_1 & 1 & EIFRSDTLYLTQDLFLPF & 16,7 & 66,7 & 45 & 62 & 14 \\
\hline M1_2 & 1 & YLTQDLFLPFYSNVTGFH & 16,7 & 77,8 & 53 & 70 & 14 \\
\hline M1_3 & 1 & TGFHTINHTFGNPVIPFK & 16,7 & 55,6 & 67 & 84 & 14 \\
\hline M1_4 & 1 & VRGWVFGSTMNNKSQSVI & 38,9 & 50 & 98 & 115 & 14 \\
\hline M1_5 & 1 & NPFFAVSKPMGTQTHTMI & 11,1 & 16,7 & 135 & 152 & 14 \\
\hline M1_6 & 1 & NAFNCTFEYISDAFSLDV & 22,2 & 55,6 & 155 & 172 & 14 \\
\hline M1_7 & 1 & CTFEYISDAFSLD & 23,1 & 61,5 & 159 & 171 & 14 \\
\hline M1_8 & 1 & DAFSLDVSEKSGN & 7,7 & 38,5 & 166 & 178 & 14 \\
\hline M1_9 & 1 & TLKPIFKLPLGINITNFR & 22,2 & 55,6 & 215 & 232 & 14 \\
\hline M1_10 & 1 & TNFRAILTAFSPAQDIW & 11,8 & 23,5 & 229 & 245 & 14 \\
\hline M1_11 & 1 & TAFSPAQDIWGTSAAAYF & 11,1 & 27,8 & 236 & 253 & 14 \\
\hline M1_12 & 1 & CSQNPLAELKCSVKSFEI & 38,9 & 50 & 278 & 295 & 14 \\
\hline M1_13 & 1 & KSFEIDKGIYQTSNFRVV & 38,9 & 77,8 & 291 & 308 & 14 \\
\hline M1_14 & 1 & IYQTSNFRVVPSGDVVRF & 38,9 & 72,2 & 299 & 316 & 14 \\
\hline M1_15 & 1 & KKISNCVADYSVLYNSTF & 33,3 & 83,3 & 343 & 360 & 14 \\
\hline M1_16 & 1 & STFFSTFKCYGVSATKL & 23,5 & 82,4 & 358 & 374 & $13 ; 14$ \\
\hline M1_17 & 1 & NIDATSTGNYNYKYRYLR & 16,7 & 55,6 & 427 & 444 & 13 \\
\hline M1_18 & 1 & YLRHGKLRPFERDISNVP & 16,7 & 50 & 442 & 459 & 14 \\
\hline M1_19 & 1 & RPFERDISNVPFS & 23,1 & 53,8 & 449 & 461 & 14 \\
\hline M1_20 & 1 & STDLIKNQCVNFNFN & 40 & 80 & 516 & 530 & 15 \\
\hline \multirow[t]{2}{*}{ M1_21 } & 1 & SSKRFQPFQQFGRDV & 20 & 73,3 & 541 & 555 & 15 \\
\hline & & Mean Identity PepMix TM 1 & 23,2 & 57,5 & & & \\
\hline M2_1 & 2 & LLRSTSQKSIVAYTMSL & 23,5 & 58,8 & 665 & 681 & 14 \\
\hline M2_2 & 2 & KSIVAYTMSLGADSS IAY & 11,1 & 72,2 & 672 & 689 & 14 \\
\hline M2_3 & 2 & TECANLLLQYGSFCTQL & 47,1 & 94,1 & 729 & 745 & 13 \\
\hline$M 2 \_4$ & 2 & VKQMYKTPTLKYFGGFNF & 22,2 & 77,8 & 767 & 784 & 14 \\
\hline M2_5 & 2 & GFMKQYGECLGDINARDL & 44,4 & 83,3 & 814 & 831 & 14 \\
\hline$M 2 \_6$ & 2 & AQKFNGLTVLPPLLTDDM & 50 & 94,4 & 834 & 851 & 14 \\
\hline $\mathrm{M} 2{ }_{-}^{-} 7$ & 2 & GAALQIPFAMQMAYRF & 25 & 100 & 873 & 888 & 14 \\
\hline M2_8 & 2 & MAYRENGIGVTQNVLY & 56,2 & 100 & 884 & 899 & 14 \\
\hline M2_9 & 2 & ESLTTTSTALGKLQDVV & 52,9 & 70,6 & 918 & 934 & 14 \\
\hline M2_10 & 2 & QALNTLVKQLSSNFGAI & 64,7 & 100 & 939 & 955 & 14 \\
\hline M2_11 & 2 & QLIRAAEIRASANLAATK & 44,4 & 100 & 993 & 1010 & 14 \\
\hline M2_12 & 2 & GTSWFITQRNFFSPQ & 40 & 73,3 & 1081 & 1095 & 15 \\
\hline $\mathrm{M} 213$ & 2 & SWFITQRNFFSPQII & 40 & 73,3 & 1083 & 1097 & 14 \\
\hline
\end{tabular}

MHC-II epitopes of the spike protein of SARS-CoV are shown with maximum identity calculations for SARS-CoV-2 and the hCoVs NL63, 229E, HKU1 and OC43. 


\section{Article}

Extended Data Table 2 | Baseline characteristics of hospitalized patients with COVID-19

\begin{tabular}{|c|c|c|c|c|c|c|}
\hline \multicolumn{7}{|c|}{ COVID-19 patients } \\
\hline ID & Severity & Gender & Age & Chief complaints at admission & ICU (y/n) & Sampling (day)* \\
\hline P01 & mild & $\mathrm{m}$ & 21 & Fever, dry cough, malaise & $\mathrm{n}$ & 39 \\
\hline P03 & mild & $\mathrm{m}$ & 45 & Fever, dry cough, runny nose & $\mathrm{n}$ & 25 \\
\hline P10 & mild & $f$ & 50 & Fever, dry cough, myalgia, cephalgia, diarrhea & $\mathrm{n}$ & 17 \\
\hline P19 & mild & $\mathrm{m}$ & 52 & Dry cough, cephalgia, arthralgia, nausea & $\mathrm{n}$ & 11 \\
\hline P23 & mild & $f$ & 44 & Fever & $\mathrm{n}$ & 5 \\
\hline P27 & mild & f & 41 & Fever, dry cough & $\mathrm{n}$ & 13 \\
\hline P06 & severe & $\mathrm{m}$ & 24 & Fever, dyspnea, malaise & $\mathrm{y}$ & 11 \\
\hline P16 & severe & $\mathrm{m}$ & 74 & Fever, dry cough, dyspnea, malaise & y & 12 \\
\hline P24 & severe & $\mathrm{m}$ & 64 & Fever, dry cough, dyspnea & $\mathrm{y}$ & 19 \\
\hline P08 & critical & $\mathrm{m}$ & 63 & Fever, dyspnea & $\mathrm{y}$ & 2 \\
\hline P12 & critical & $\mathrm{m}$ & 75 & Fever, dyspnea, malaise & $\mathrm{y}$ & 8 \\
\hline P14 & critical & $\mathrm{m}$ & 81 & Fever, dyspnea & $\mathrm{y}$ & 8 \\
\hline P15 & critical & $\mathrm{m}$ & 54 & Dry cough, dyspnea & $y$ & 6 \\
\hline P20 & critical & $f$ & 53 & Dry cough, dyspnea & $\mathrm{y}$ & 11 \\
\hline
\end{tabular}

$f$, female; $m$, male; $n$, no; $y$, yes.

*Days after onset of symptoms. 
Extended Data Table 3 | Baseline characteristics of healthy donors

\begin{tabular}{|c|c|c|c|c|c|c|c|}
\hline \multicolumn{8}{|c|}{ Healthy donors } \\
\hline ID & Gender & Age & Health status & ID & Gender & Age & Health status \\
\hline HD01 & $\mathrm{m}$ & 56 & & HD38 & $f$ & 30 & Allergies \\
\hline HD02 & $\mathrm{m}$ & 48 & & HD39 & $f$ & 41 & \\
\hline HD03 & $\mathrm{m}$ & 37 & & HD40 & $f$ & 53 & \\
\hline HD04 & $f$ & 40 & & HD41 & $\mathrm{m}$ & 42 & \\
\hline HD05 & $f$ & 22 & & HD42 & $f$ & 55 & \\
\hline HD06 & $\mathrm{m}$ & 30 & & HD43 & $\mathrm{m}$ & 25 & \\
\hline HD07 & $\mathrm{m}$ & 25 & & HD44 & $f$ & 53 & Hashimoto Thyreoiditis \\
\hline HD08 & $\mathrm{m}$ & 41 & & HD45 & $f$ & 47 & \\
\hline HD09 & $\mathrm{m}$ & 37 & & HD46 & $f$ & 31 & \\
\hline HD10 & $\mathrm{m}$ & 40 & & HD47 & $f$ & 46 & \\
\hline HD11 & $f$ & 28 & & HD48 & $\mathrm{m}$ & 31 & \\
\hline HD12 & $f$ & 43 & & HD49 & $m$ & 44 & \\
\hline HD13 & $\mathrm{m}$ & 44 & Allergies & HD50 & $f$ & 60 & \\
\hline HD14 & $f$ & 27 & & HD51 & $f$ & 43 & \\
\hline HD15 & $m$ & 32 & & HD52 & $f$ & 20 & \\
\hline HD16 & $m$ & 24 & & HD53 & $f$ & 46 & \\
\hline HD17 & $\mathrm{m}$ & 42 & & HD54 & $\mathrm{m}$ & 24 & \\
\hline HD18 & $\mathrm{m}$ & 40 & & HD55 & $f$ & 40 & \\
\hline HD19 & $f$ & 26 & & HD56 & $f$ & 40 & \\
\hline HD20 & $f$ & 33 & & HD57 & $f$ & 50 & \\
\hline HD21 & $\mathrm{m}$ & 30 & & HD58 & $f$ & 30 & \\
\hline HD22 & $\mathrm{m}$ & 29 & & HD59 & $f$ & 46 & Allergies \\
\hline HD23 & $f$ & 38 & & HD60 & $f$ & 31 & \\
\hline HD24 & $m$ & 25 & & HD61 & $f$ & 52 & \\
\hline HD25 & $\mathrm{m}$ & 48 & & HD62 & $f$ & 53 & Adenoma (surgically removed) \\
\hline HD26 & $f$ & 30 & & HD63 & $f$ & 40 & \\
\hline HD27 & $\mathrm{m}$ & 64 & & HD64 & $f$ & 27 & \\
\hline HD28 & $f$ & 22 & & HD65 & $\mathrm{m}$ & 52 & \\
\hline HD29 & $f$ & 40 & & HD66 & $f$ & 42 & \\
\hline HD30 & $f$ & 30 & & HD67 & $f$ & 25 & \\
\hline HD34 & $f$ & 55 & & HD68 & $\mathrm{m}$ & 38 & \\
\hline HD35 & $\mathrm{m}$ & 38 & Thyroid dysfunction & HD70 & $f$ & 22 & \\
\hline HD36 & $\mathrm{m}$ & 27 & & HD71 & $\mathrm{m}$ & 30 & \\
\hline HD37 & $f$ & 26 & & HD72 & $f$ & 64 & \\
\hline
\end{tabular}




\section{Article}

Extended Data Table 4 | Baseline characteristics of seven additional patients with COVID-19

\begin{tabular}{lllllll}
\hline ID & Severity & Gender & Age & Chief complaints at admission & ICU & Sampling (day) \\
(y/n)
\end{tabular}

Seven patients with COVID-19 were enrolled for the analysis of cytokine expression; cytokines were stained with antibodies and expression levels were analysed using flow cytometry.

${ }^{*}$ Days after onset of symptoms. 


\section{Reporting Summary}

Nature Research wishes to improve the reproducibility of the work that we publish. This form provides structure for consistency and transparency in reporting. For further information on Nature Research policies, see Authors \& Referees and the Editorial Policy Checklist.

\section{Statistics}

For all statistical analyses, confirm that the following items are present in the figure legend, table legend, main text, or Methods section.

n/a Confirmed

$\square$ \. The exact sample size $(n)$ for each experimental group/condition, given as a discrete number and unit of measurement

$\square \bigotimes$ A statement on whether measurements were taken from distinct samples or whether the same sample was measured repeatedly

The statistical test(s) used AND whether they are one- or two-sided

$\square$ Only common tests should be described solely by name; describe more complex techniques in the Methods section.

Х $\square$ A description of all covariates tested

$\square$ \A description of any assumptions or corrections, such as tests of normality and adjustment for multiple comparisons

$\square$ A full description of the statistical parameters including central tendency (e.g. means) or other basic estimates (e.g. regression coefficient)

AND variation (e.g. standard deviation) or associated estimates of uncertainty (e.g. confidence intervals)

W For null hypothesis testing, the test statistic (e.g. $F, t, r$ ) with confidence intervals, effect sizes, degrees of freedom and $P$ value noted

$\triangle \square$ Give $P$ values as exact values whenever suitable.

Х $\square$ For Bayesian analysis, information on the choice of priors and Markov chain Monte Carlo settings

Х $\square$ For hierarchical and complex designs, identification of the appropriate level for tests and full reporting of outcomes

$\square$ Estimates of effect sizes (e.g. Cohen's $d$, Pearson's $r$ ), indicating how they were calculated

Our web collection on statistics for biologists contains articles on many of the points above.

\section{Software and code}

Policy information about availability of computer code

Data collection Miltenyi MACSquantify software v2.13 was used for flow cytometry data collection.

Data analysis All the softwares and there version information are shown her. FlowJo (v9.9.6) was used for all FACS analyses. Microsoft Excel (v.14.1.0) was used to collect and arrange data and patient / donor information. GraphPad Prism (v5.0b and v8.4.2. (464)) was used to analyze data and create plots.

Sequence alignments have been performed using R (v3.6.1) including package ClustalX (Larkin,M.A., Blackshields, G., Brown, N.P.,

Chenna, R., McGettigan, P.A., McWilliam, H., Valentin, F., Wallace, I.M., Wilm, A., Lopez, R., Thompson, J.D., Gibson, T.J., Higgins, D.G.

(2007) Clustal W and Clustal X version 2.0. Bioinformatics, 23:2947-2948.) and using the Needlemann-Wunsch algorithm.

For manuscripts utilizing custom algorithms or software that are central to the research but not yet described in published literature, software must be made available to editors/reviewers. We strongly encourage code deposition in a community repository (e.g. GitHub). See the Nature Research guidelines for submitting code \& software for further information.

\section{Data}

Policy information about availability of data

All manuscripts must include a data availability statement. This statement should provide the following information, where applicable:

- Accession codes, unique identifiers, or web links for publicly available datasets

- A list of figures that have associated raw data

- A description of any restrictions on data availability

All flow cytometry data are made available in the FlowRepository, org (experiment ID: FR-FCM-Z2K3). An additional Supplementary Figure displaying the individual gating strategy for all donors is available in the online version of the paper. 


\section{Field-specific reporting}

Please select the one below that is the best fit for your research. If you are not sure, read the appropriate sections before making your selection. $\bigotimes$ Life sciences $\quad \square$ Behavioural \& social sciences $\quad \square$ Ecological, evolutionary \& environmental sciences

For a reference copy of the document with all sections, see nature.com/documents/nr-reporting-summary-flat.pdf

\section{Life sciences study design}

All studies must disclose on these points even when the disclosure is negative.

Sample size No sample size calculation was performed. Within COVID-19 patients, 83\% exhibited T cell reactivity to the Spike glycoprotein of SARS-CoV2. Within the healthy donors recruited, $35 \%$ were identified as reactive healthy donors. With the proportions, the recruited numbers of subjects are sufficient.

Data exclusions No data were excluded from the analysis.

Replication We remeasured several donors (accompanied by anti-SARS-CoV-2 IgG antibody testing) at later timepoints and used another Spike glycoprotein peptide pool from Miltenyi to ensure reproducibility of T cell reactivity in SARS-CoV-2 naive donors.

Randomization No randomization was performed since it was not applicable to the study.

Blinding Blinding was not applicable to this study.

\section{Reporting for specific materials, systems and methods}

We require information from authors about some types of materials, experimental systems and methods used in many studies. Here, indicate whether each material, system or method listed is relevant to your study. If you are not sure if a list item applies to your research, read the appropriate section before selecting a response.

Materials \& experimental systems

\begin{tabular}{l|l}
\hline Ia & Involved in the study \\
\hline & $\square$ Antibodies \\
$\square$ & $\square$ Eukaryotic cell lines \\
$\square$ & $\square$ Clinical data
\end{tabular}

\begin{tabular}{l|l} 
Methods \\
\hline n/a & Involved in the study \\
$\square$ & $\square$ ChIP-seq \\
$\square$ & $\square$ Flow cytometry \\
$\triangle$ & $\square$ MRI-based neuroimaging
\end{tabular}

\section{Antibodies}

Antibodies used

CD69-APCCy7 BioLegend Cat\# 310914, RRID:AB_314849

CD4-BV605 BioLegend Cat\# 300556, RRID:AB_2564391

CD8-PerCp BioLegend Cat\# 344708, RRID:AB_1967149

IFNg-AlexaFluor700 BioLegend Cat\# 502520, RRID:AB_528921

TNFa-PB BioLegend Cat\# 502920, RRID:AB_528965

CD38-PeVio770 Miltenyi Biotec Cat\# 130-118-982, RRID:AB_2751601

HLADR-VG Miltenyi Biotec Cat\# 130-111-795, RRID:AB_2652164

CD154-APC Miltenyi Biotec Cat\# 130-113-603, RRID:AB_ 2726191

CD137-PE BD Biosciences Cat\# 555956, RRID:AB_396252

CD154-BV421 BioLegend Cat\# 310824, RRID:AB_2562721

IL-2-APC BD Biosciences Cat\# 341116, RRID:AB_400574

IL-17A-APCCy7 BioLegend Cat\# 512320, RRID:AB_10613103

CCR7-AlexaFluor488 BioLegend Cat\# 353206, RRID:AB_10916389

CD45RA-PeCy7 BioLegend Cat\# 304126, RRID:AB_10708879

CD3-V500 BD Biosciences Cat\# 560770, RRID:AB_1937322

Validation

All antibodies are established, well described and published elsewhere. Informations are accessible on the manufacturers websites under Catalogue or RRID numbers. 
Policy information about studies involving human research participants

Population characteristics The study included:

- 18 COVID-19 patients (Table 1):age mean 52.6, range: 21-81 yrs; gender: female ratio 27.8\%; sampling day (post symptom onset): mean 14.9 , range: $2-39$

- 7 additional COVID-19 patients (Extended data Table 3): age mean 53, range: 10-79 yrs; gender: female ratio 14.3\%; sampling day (post symptom onset): mean 31.6, range: $10-53$

- 68 healthy donors (age mean 41.93, range: 20-64 yrs; gender: female ratio 59\%)

All healthy donors stated to be free of symptoms indicating an acute infection.

Recruitment

Patients were hospitalised in the Charité. The patients were selected based on the disease severiyt to achieve a balanced representation of the three disease serverity groups.

Ethics oversight

Institutional Review Board of the Charité

Note that full information on the approval of the study protocol must also be provided in the manuscript.

\section{Flow Cytometry}

Plots

Confirm that:

The axis labels state the marker and fluorochrome used (e.g. CD4-FITC).

The axis scales are clearly visible. Include numbers along axes only for bottom left plot of group (a 'group' is an analysis of identical markers).

$\bigotimes$ All plots are contour plots with outliers or pseudocolor plots.

$\bigotimes$ A numerical value for number of cells or percentage (with statistics) is provided.

Methodology

Sample preparation

Peripheral blood mononuclear cells (PBMC) were isolated from heparinized whole blood by gradient density centrifugation according to manufacturer's instructions (Leucosep tubes, Greiner; Biocoll, Bio\&SELL). Stimulation was conducted with 5x10e6 PBMC in RPMI 1640 medium (Gibco) supplemented with 10\% heat inactivated AB serum (Pan Biotech), $100 \mathrm{U} / \mathrm{ml}$ penicillin (Biochrom), $0.1 \mathrm{mg} / \mathrm{ml}$ streptomycin (Biochrom), and PepMixTM SARS-CoV-2 in the presence of $1 \mu \mathrm{g} / \mathrm{ml}$ purified anti-CD28 (clone CD28.2, BD Biosciences). PepMixTM SARS-CoV-2 (Spike Glycoprotein) subpool 1 covering the N-terminal aa 1-643 (abbreviated to "S-I (N-term)") containing 158 15-mers overlapping by 11 and PepMixTM SARS-CoV-2 (Spike Glycoprotein) subpool 2 covering the C-terminal aa 633-1273 (abbreviated to "S-II (C-term)") (JPT) containing 156 15-mers overlapping by 11 and one 17-mer at C-terminus were used at $1 \mu \mathrm{g} / \mathrm{ml}$ per peptide, respectively. Stimulation controls were performed with equal concentrations of DMSO in PBS (unstimulated) or $1.5 \mathrm{mg}$ SEB/1.0 mg TSST1 (Sigma-Aldrich) and PepMixTM CMV pp65 (Miltenyi) as positive controls, respectively. Incubation was performed at $37^{\circ} \mathrm{C}, 5 \% \mathrm{CO} 2$ for $14 \mathrm{~h}$ with $10 \mu \mathrm{g} / \mathrm{ml}$ brefeldin A (Sigma- Aldrich) added after $2 \mathrm{~h}$. Stimulation was stopped by incubation in $20 \mathrm{mM}$ EDTA for $5 \mathrm{~min}$ and surface staining conducted for $15 \mathrm{~min}$ with the following fluorochrome conjugated antibodies titrated to their optimal concentrations: CD38-PE-Vio770 (clone REA671, Miltenyi), CD69-APC-Cy7 (FN50, Biolegend), HLAD-DR-VioGreen (REA805, Miltenyi), CD4-BrilliantViolet605 (RPA-T4, Biolegend), CD8-PerCP (SK1, Biolegend) with $1 \mathrm{mg} / \mathrm{ml}$ Beriglobin (CSL Behring) added prior to the staining. For exclusion of dead cells, Zombie Yellow fixable viability staining (Biolegend) was added for the last 10 min of incubation. Fixation and permeabilization were performed with eBioscienceTM FoxP3 fixation and PermBuffer (Invitrogen) according to the manufacturer's protocol and intracellular staining carried out for $30 \mathrm{~min}$ in the dark at room temperature with Beriglobin added prior to intracellular staining with 4-1BB-PE (clone 4B4-1, BD), CD40L-APC (5C8, Miltenyi) and Ki-67-AlexaFluor488 (B56, BD). For intracellular cytokine staining, we employed different antibodies. Surface staining was performed with CD3-V500 (SP34-2, BD), CD8-PerCP (SK1, Biolegend), CD4-BrilliantViolet605 (RPA-T4, Biolegend), CCR7-AlexaFluor488 (G043H7, Biolegend), CD45RA-PE-Cy7 (HI100, Biolegend). IFN- $\gamma$-AlexaFluor700, CD4OL-BrilliantViolet421 (24-31, Biolegend), IL-2-APC (5344.111, BD), 4-1BB-PE (4B4-1, BD) and IL-17A-APC-Cy7 (BL168, Biolegend) were utilized for intracellular staining after fixation and permeabilization using BD FACSLysing Buffer and BD Perm2 Buffer, according to manufacturer's instructions.

Instrument

Samples were measured on a MACSQuant ${ }^{\circledR}$ Analyzer 16 and the instrument performance monitored daily with Rainbow Calibration Particles (BD).

Software

Miltenyi MACSquantif software (v2.13) and FlowJo (v9.9.6)

Cell population abundance

Cells have not been enriched or sorted, except by the generation of SARS-CoV-2-S-II reactive CD4 T cell lines. Data are shown within ex vivo stimulated peripheral blood mononuclear cells.

Gating strategy

All recorded events were gated according to FSC and SSC as lymphocytes; single cells were further selected using FSC-H vs. FSC$W$ and again using SSC-H vs. SSC-W. Subsequently living cells were identified as ZombieYellow negative cells gated against CD4BV605. An artefact population in some samples (probably induced by DMSO) was observed disturbing data analysis and was gated out using V500 vs V450. The subsequent gating scheme is depicted in Fig.2a and Fig. 3a.

Tick this box to confirm that a figure exemplifying the gating strategy is provided in the Supplementary Information. 